JOINT TRANSPORTATION RESEARCH PROGRAM

FHWA/IN/JTRP-2007/11

Final Report

DURABILITY AND RETRO-REFLECTIVITY OF PAVEMENT MARKINGS

(SYNTHESIS STUDY)

Yi Jiang

January 2008 
Final Report

FHWA/IN/JTRP-2007/11

\title{
DURABILITY AND RETRO-REFLECTIVITY OF PAVEMENT MARKINGS (SYNTHESIS STUDY)
}

\author{
by \\ Yi Jiang, Ph.D., P.E. \\ Department of Building Construction Management \\ Purdue University \\ Joint Transportation Research Program \\ Project No. C-36-54HHH \\ File No. 3-3-60 \\ SPR-3000 \\ Prepared in Cooperation with the \\ Indiana Department of Transportation and the \\ U.S. Department of Transportation \\ Federal Highway Administration
}

The contents of this report reflect the views of the authors, who are responsible for the facts and the accuracy of the data presented herein. The contents do not necessarily reflect the official views or policies of the Indiana Department of Transportation or the Federal Highway Administration at the time of publication. This report does not constitute a standard, specification, or regulation.

Purdue University

West Lafayette, Indiana 47907

January 2008 
TECHNICAL REPORT STANDARD TITLE PAGE

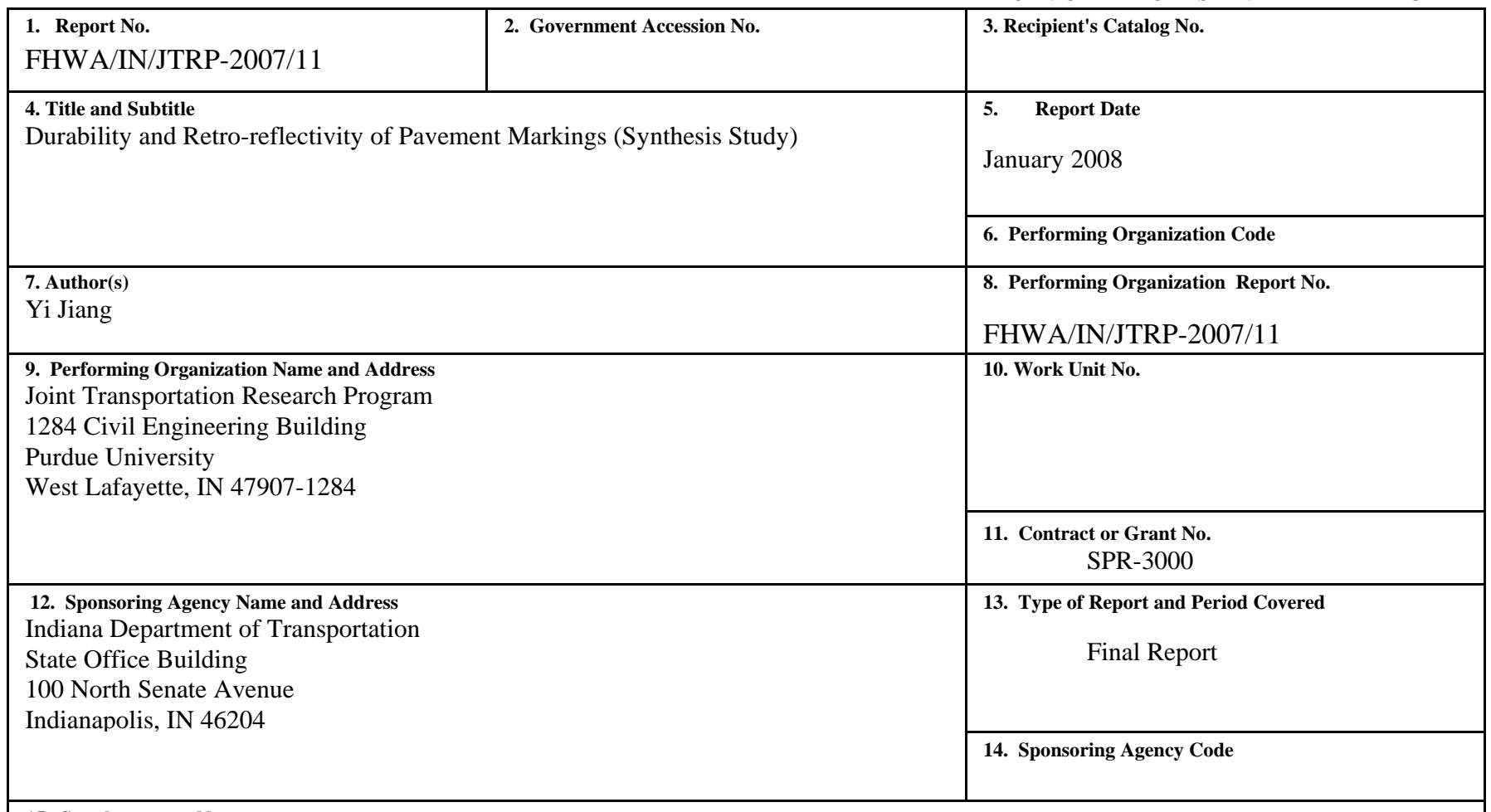

\section{Supplementary Notes}

Prepared in cooperation with the Indiana Department of Transportation and Federal Highway Administration.

\section{Abstract}

Waterborne paints are used to paint pavement markings (edgelines and centerlines) to provide guidance for motorists. The painted markings need to be repainted periodically as their retro-reflectivity deteriorates. The Indiana Department of Transportation (INDOT) repaints pavement markings at least annually. INDOT engineers would like to determine the feasibility of extending the time intervals of repainting pavement markings on at least some types of roadways. The purpose of this synthesis study is to accomplish the following: (1) to locate and assemble documented information on pavement marking durability; (2) to learn what criteria have been used in other states in measuring retro-reflectivity and scheduling pavement marking painting; (3) to determine the necessity of conducting full scale study on INDOT pavement markings; (4) to identify the type and cost of equipment required for retro-reflectivity measurements and conditions of operation of the equipment; (5) to organize, evaluate, and document the useful information that is acquired; and (6) to provide recommendations based on the evaluated information.

This report presents the findings of the synthesis study on various pavement marking materials. It was found in this study that many state highway agencies have evaluated several types of pavement marking materials. The evaluation results include performance, cost, service life, and retro-reflectivity measuring equipment of marking materials. However, the results could vary from different sates. The information gathered through this study will provide INDOT engineers the state-of-practice of pavement marking materials in this country.

\section{Key Words}

Pavement marking, retro-reflectivity, waterborne paints, thermoplastics, epoxy

\section{Distribution Statement}

No restrictions. This document is available to the public through the National Technical Information Service, Springfield, VA 22161

\begin{tabular}{|c|c|c|c|}
\hline $\begin{array}{c}\text { 19. Security Classif. (of this report) } \\
\text { Unclassified }\end{array}$ & $\begin{array}{c}\text { 20. Security Classif. (of this page) } \\
\text { Unclassified }\end{array}$ & 21. No. of Pages & 58 \\
\hline
\end{tabular}




\section{ACKNOWLEDGMENTS}

This synthesis study was sponsored by the Indiana Department of Transportation (INDOT) in cooperation with the Federal Highway Administration through the Joint Transportation Research Program. The author would like to thank the study advisory committee members, Dwayne Harris and Carl Tuttle of INDOT, and David Unkefer of FHWA, for their valuable assistance and technical guidance. Their efforts and useful inputs are acknowledged and every much appreciated. 


\section{TABLE OF CONTENTS}

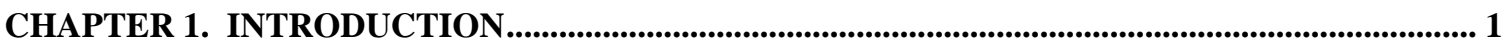

CHAPTER 2. THE USES OF PAVEMENT MARKING MATERIALS IN THE STATES................. 3

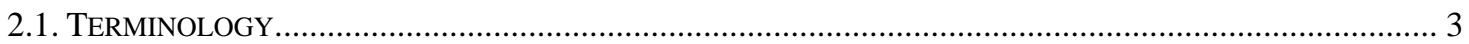

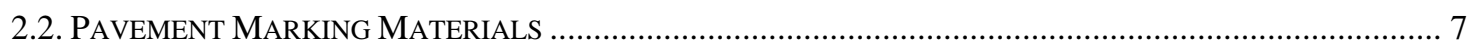

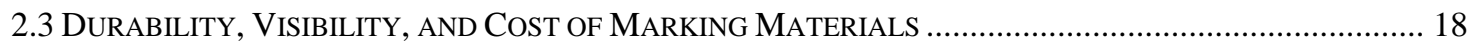

2.3 EQUIPMENT FOR MEASURING THE RETROREFLECTIVITY OF PAVEMENT MARKINGS .......................... 37

CHAPTER 3. THE STATE OF PRACTICE OF PAVEMENT MARKING APPLICATIONS IN

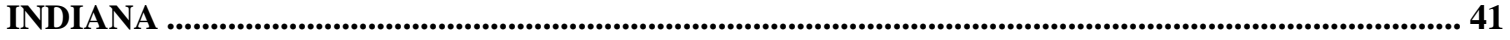

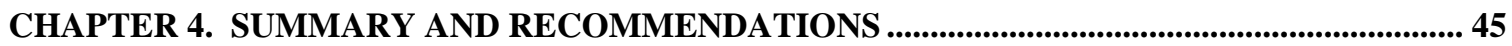

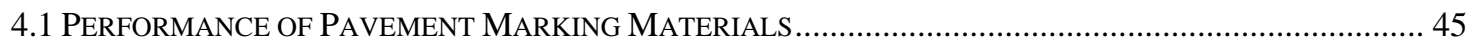

4.2 RETROREFLECTIVITY MEASURING DEVICES .................................................................. 51

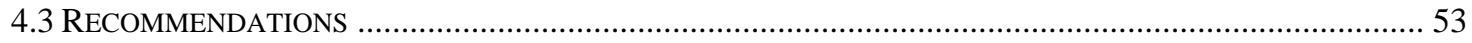

REFERENCES ....................................................................................................................................... 57 


\section{CHAPTER 1. INTRODUCTION}

Waterborne paints are used to paint pavement markings (edgelines and centerlines) to provide guidance for motorists. The painted markings need to be repainted periodically as their retroreflectivity deteriorates. The Indiana Department of Transportation (INDOT) repaints pavement markings at least annually. However, some states repaint pavement markings at two-year or longer cycles on certain roads. Thus, INDOT engineers would like to determine the feasibility of extending the time intervals of repainting pavement markings on at least some types of roadways. Currently, there are no federal required minimum retrorefelctivity for pavement markings. Therefore, INDOT engineers would like to find out the minimum retroreflectvity in determining the end life of pavement markings. In 2004, the cost for the INDOT pavement marking painting was about $\$ 2.4$ millions. If it is practical for INDOT to extend the repainting cycles of pavement marking, it would result in significant cost savings. To address these questions and concerns, it is desirable to study the paint materials that INDOT uses for pavement markings with appropriate equipment for measurements of pavement marking retroreflectivity. This would require a proper study plan and selection and purchase of a mobile retroreflectometer. The Focus Group under the Joint Transportation Research Program (JTRP) between INDOT and Purdue University recommended that, before a full scale study is conducted, this Synthesis Study be undertaken to identify the research results related to retrorefelctivity of pavement markings and appropriate equipment for retroreflectivity measurements. 
The purpose of this synthesis study is to accomplish the following: (1) to locate and assemble documented information on pavement marking durability; (2) to learn what criteria have been used in other states in measuring retroreflectivity and scheduling pavement marking painting; (3) to determine the necessity of conducting full scale study on INDOT pavement markings; (4) to identify the type and cost of equipment required for retroreflectivity measurements and conditions of operation of the equipment; (5) to organize, evaluate, and document the useful information that is acquired; and (6) to provide recommendations based on the evaluated information. 


\section{CHAPTER 2. THE USES OF PAVEMENT MARKING MATERIALS IN THE STATES}

\subsection{Terminology}

Montebello and Schroeder (2000) pointed out that the reader's ability to understand the various pavement marking materials and their associated benefits and drawbacks is dependent upon a basic understanding of pavement marking terminology. Because of the large number of manufacturers many terms are used to describe a single type of marking material. They provided the following definitions of the most prevalent expressions of pavement marking related terms:

Alkyd Paints: Alkyds are conventional paints that are solvent-based. They are quick drying paints that no longer contain hazardous amounts of volatile organic carbons. They do, however, contain a highly flammable base material and require the use of harsh solvents to remove the paint from equipment.

Centerline: The yellow line separating opposing traffic.

Conventional Products: Conventional products include latex and alkyd paints. These products have a shorter life span than durable products.

Durable Products: Durable products include epoxy, thermoplastics and poly preformed tapes. These products generally have a longer life span than conventional products.

Durability: Durability refers to a product's ability to withstand damage. The life cycle of a product is taken into consideration when evaluating durability. 
Edge Line: White or yellow solid lines. White solid lines delineate the right-most driving lane from the shoulder or ditch of the road. Yellow solid lines delineate the leftmost lane of traffic from the shoulder or ditch of the roadway, or the left edge of a oneway roadway.

Epoxy: Often referred to as “epoxy paint.” Epoxy is a durable pavement marking material that is made up of two components. One component is the pigment and the second component is the hardener. Each component is heated separately and then thoroughly mixed and applied at a temperature of $43^{\circ}+1^{\circ} \mathrm{C}\left(110^{\circ}+30^{\circ} \mathrm{F}\right)$. Epoxy comes in two forms: fast-dry and slow-dry.

Glass Beads: Glass beads are tiny spherical glass balls that are used to make pavement marking materials retroreflective. Glass beads are dropped on top of freshly applied conventional paints and durable materials such as epoxies. In some cases, portions of the beads are mixed in with paint before it is applied (pre-mixed paint). Glass beads can also be untreated or treated. Treated glass beads have a coating on their surface that enables the bead to sink into the paint, while the untreated beads float on the surface. Having a portion of the beads on the surface and in the paint allow continued retroreflectivity as the paint wears. The same result can be achieved by using the pre-mixed paints and dropping on untreated beads. The proper application of beads is key in creating the marking's retroreflectivity.

Heavy Metals: Toxic materials defined by the United States Environmental Protection Agency that are not allowed to be included in pavement marking materials because of their threat to the environment and to the users of the product. Toxic heavy metals include lead, cadmium, mercury and hexavalent chromium. 
High-Volume Roadway: Roadways with an AADT of 10,000 or greater.

Lane Line: The lane line is the white broken (skip) line that delineates lanes of concurrent-flow traffic on multi-lane roads.

Latex Paints: A pavement marking that is water-based. It is typically considered a conventional material; however, it does come in a mid-durable formula. Latex is a quick dry material.

Lead: Lead is a toxic heavy metal that was a component of conventional paints. The use of lead is no longer allowed under most circumstances.

Oil-Based Paints: Oil-based paints are the same as alkyd paints (solvent-based).

Paint: Paint is a conventional pavement marking material. It can be solvent-based or water-based. Often epoxy is referred to as “epoxy paint," even though it is not a paint or a conventional pavement marking material.

Pavement Markings: Edge lines, centerlines, lane lines and symbols that are placed on pavement or curb surfaces. They are used to provide direction to drivers.

Pre-mix: Conventional paint with glass beads in it. Pre-mix is available in latex and alkyd paints.

Plastic Preformed Pavement Marking Material: Often referred to as "tape," this material is durable. The material is made up of plastic that is heated into the pavement surface. Plastic preforms can be used for symbols, legends and crosswalks.

Poly Preformed Pavement Marking Material: Often referred to as “tape,” this material is durable. The material can be inlaid into freshly placed bituminous surfaces. It can also be glued into place on older bituminous or concrete surfaces. 
Quick-Dry Paints: Paints that dry in three minutes or less are called quick-dry. They may also be referred to as fast-dry.

Retroreflectivity: Retroreflectivity refers to reflection in which originating light is turned in directions close to the direction from which it came. The retroreflectivity of the pavement marking material makes it visible to drivers at night when their vehicle's headlights reflect off the material. It is usually measured in candelas/lux/square meter, which is equivalent to candelas/foot-candle/square foot. Even though the Manual on Uniform Traffic Control Devices does not specify a minimum retroreflective level for pavement marking materials, the Minnesota Department of Transportation views the minimum acceptable initial retroreflectivity level to be $180 \mathrm{mcd} / \mathrm{m}^{2} / \mathrm{lux}$ for yellow material and $275 \mathrm{mcd} / \mathrm{m}^{2} / \mathrm{lux}$ for white material (Mn/DOT specs for alkyd and latex paints).

Slow-Dry Materials: Products that take longer than three minutes to dry are called slowdry. They are usually the epoxies or thermoplastics. Traffic control such as coning and/or flagging is required when applying these materials.

Solvent-borne Paints: Solvent-borne paints are alkyd paints. The new formula no longer contains hazardous amounts of volatile organic compounds.

Tapes: Tapes are also referred to as "preforms.” This is a durable marking product that is inlaid on freshly laid bituminous surfaces or is tamped onto concrete and older bituminous surfaces.

Temporary Tape: Temporary tape is a pavement marking material that is used at many construction sites or work zones for a short period of time. It is often used to delineate lane shifts and changes on newly completed road surfaces. Temporary tape is used in 
these instances so that the newly completed surface is not damaged by abrasive cleaning techniques needed to remove the more permanent marking materials. The material comes on a roll and is laid on top of the road surface and tamped down. When construction is complete, the material can be lifted off the road surface.

Thermoplastics: Thermoplastics are a durable pavement marking material composed of glass beads, pigments, binders (plastics and resins) and fillers. There are two types of thermoplastics: hydrocarbon and alkyd. Hydrocarbon thermoplastics are made from petroleum-derived resins; and alkyd thermoplastics are made from wood-derived resins. Thermoplastics are originally in a granular or block form. They are then heated to a temperature of at least $400_{\mathrm{o}} \mathrm{F}$ and sprayed onto the pavement.

Thermosets: Epoxy and polyester are thermosets. Thermosets are durable pavement marking materials that are sprayed onto the road surface with glass beads dropped on top. Volatile Organic Compounds: Volatile organic compound means any organic compound that participates in atmospheric photochemical reactions. These reactions are not good for the environment and as a result, many of the products that have high levels of these compounds have been prohibited.

Water Borne Paints: Water-borne paints are latex paints.

\subsection{Pavement Marking Materials}

Various types of materials are used for pavement markings in this country. The effects and performances of these materials have been examined by a number of state and federal highway agencies. Gates, Hawkins and Rose (2003) studied the effectiveness of pavement marking materials on concrete pavements. They indicated that some state 
DOTs have had great success with thermoplastic on concrete, while many others discourage its use on concrete. Their study results showed that the thermoplastic marking material used in Texas did not perform well on concrete pavements, while epoxy marking materials performed better. As they stated, many materials exist that may be used for pavement markings on concrete roadway surfaces. However the service life and cost of the various materials vary greatly. As with other traffic control devices, maintaining pavement markings that are highly visible and long lasting presents a major challenge to transportation agencies.

Thomas and Schloz (2001) did a synthesis on durability and cost-effectiveness of pavement marking materials for the Iowa Department of Transportation. They indicated that pavement marking technology is a continually evolving subject. There are numerous types of materials used in the field today, including paint, epoxy, tape, and thermoplastic. Each material has its own set of unique characteristics related to durability, retroreflectivity, installation cost, and life-cycle cost. In addition to durability and visibility, cost must also be considered in order to determine the cost-effectiveness of pavement marking materials. Cost can be a critical factor, especially when there is a set amount of available funding. When evaluating cost, it is important to consider not only the cost of the material, but also the cost of the crew and the application equipment necessary. One should also check for manufacturer guarantees over a specified time. Some manufacturers replace deteriorating materials free of charge if their product does not achieve certain guidelines (Clark and Sanders, 1993). 
A National Cooperative Highway Research Program (NCHRP) sponsored study (Bahar, et al., 2006) analyzed the safety effect of retroreflectivity of longitudinal pavement markings and markers over time on non-intersection locations during nondaylight conditions. The NCHRP study utilized the pavement marking data collected through the National Transportation Product Evaluation Program (NTPEP) to evaluate the retroreflectivity of different types of pavement marking materials. NTPEP is an engineering and technical services program operated by the American Association of State Highway and Transportation Officials (AASHTO). The program pools the physical and professional resources of member states to evaluate commercially available products for use by state and local agencies. These products are typically evaluated using established AASHTO and ASTM-specified tests and when standards do not exist, the NTPEP Oversight Committee convenes and establishes evaluation protocols through AASHTO ballot. A wide variety of products are tested, including pavement marking materials, sign sheeting materials, markers and adhesives, and flexible delineators. Many state agencies use NTPEP test results to screen commercially available products for prequalification of materials for use in their states, while others, such as Texas, continue to conduct much of their own testing. A survey of state transportation agencies was conducted in 2001 to determine the degree of state reliance on NTPEP results and gauge their attitudes towards the NTPEP program (TransTech Management Inc., 2001). The survey revealed that while many agencies continue to conduct their own testing of products, two thirds (67\%) of the states surveyed indicated that NTPEP saves time and costs by reducing the need for state testing, while the majority (57\%) intended to make greater use of NTPEP test results in the near future. Based on the NCHRP study, the 
major types of pavement marking materials used in the states include the following (Bahar, et al., 2006):

1. Waterborne Paints: In 1994, the FHWA released a memorandum describing the impact of a new Environmental Protection Agency (EPA) regulation on the use of pavement marking material. The regulation was developed to reduce Architectural and Industrial Maintenance (AIM) coating emissions by $40 \%$ by 2004 . It led to the establishment of a $150 \mathrm{~g} / \mathrm{L}(1.25 \mathrm{lb} / \mathrm{gal})$ limit by 2000 and a $100 \mathrm{~g} / \mathrm{L}(0.83$ lb/gal) limit by 2004 on Volatile Organic Compound (VOC) content for pavement marking materials. Over the past 10 years, transportation agencies in the United States have gradually replaced conventional solvent paints with waterborne paints (that have low VOC contents) and other newer pavement marking materials. Waterborne traffic paints are the most widely used and least expensive pavement marking material available. Glass beads are either pre-mixed into the paint or dropped onto the waterborne paint while the marking is wet to provide retroreflectivity. Paints generally provide equal performance on asphalt and concrete pavements but have the shortest service life of all pavement marking materials. Waterborne paints are single-component paints that are ready for application and do not require additional ingredients (Migletz \& Graham, 2002). They are environmentally friendly, are much easier to handle than conventional solvent paints, and greatly decrease the safety hazard to workers given their low VOC content (typically less than $150 \mathrm{~g} / \mathrm{L}$ or $1.25 \mathrm{lb} / \mathrm{gal}$ of VOC). This, coupled with the low cost, is the major advantage of waterborne paints (Andrady, 1997). 
Compared to other pavement marking materials, waterborne paints wear off rapidly and lose retroreflectivity quickly after being exposed to factors such as high traffic volumes and winter maintenance activities. Although waterborne paints are still the most widely used pavement marking material, none of the 19 state agencies surveyed by Gates et al. (2003) recommended them as the top performing long-term material. Several state agencies even stated that they use waterborne paint as an interim marking material until they can apply something more durable. McGinnis (2001) further added that given the short service life of waterborne paint markings, many state agencies often choose to repaint those markings on a fixed schedule instead of restriping when some objective measure such as retroreflectivity drops below a specified threshold. With the easy availability of more durable pavement marking materials on the market, Gates et al. (2003) suggested that waterborne paint is not a suitable marking material for high-volume roadways despite its inexpensive application cost.

2. Conventional Solvent Paints: Conventional solvent paints are single-component paints that contain a binder resin, pigments or fillers, and solvents or additives. Similar to waterborne paints, glass beads are either premixed into the paint or dropped onto the paint while the marking is still wet to provide retroreflectivity. Solvent-borne paints are normally classified according to the resin binder used in the formulation. Some common types of solvent paints include alkyd, acrylic, and chlorinated polyolefins or chlorinated rubber (Migletz \& Graham, 2002; Andrady, 1997). Due to the ingredients used in the formulation of these paints, they 
typically contain $440 \mathrm{~g} / \mathrm{L}$ (3.70 lb/gal) of VOCs, far exceeding the maximum of $150 \mathrm{~g} / \mathrm{L}(1.25 \mathrm{lb} / \mathrm{gal})$ recommended by the EPA. Although some solvent-borne paints, such as chlorinated-rubber paints, have been shown to be very durable (Andrady, 1997), the use of these paints have gradually diminished with the introduction of the EPA limits on VOCs.

3. Thermoplastic: Thermoplastics materials have been used in the United States since the 1950s and consist of four basic components: binder, pigment, glass beads, and filler (sand or calcium carbonate). There are two types of thermoplastics: hydrocarbon and alkyd (Migletz \& Graham, 2002). Due to its low VOC content, moderate cost and durability, it is one of the most widely used pavement marking materials. In fact, the vast majority of longitudinal pavement markings in some states, such as Texas, are thermoplastic. One of the added advantages of using thermoplastic is that the material can be re-applied over older thermoplastic markings, thereby refurbishing the older marking as well as saving on the costs of removing old pavement markings. Although thermoplastic materials usually perform very well on all types of asphalt surfaces, there have been mixed results when they have been applied on concrete pavements (Gates et al., 2003; \& Ahmad et al., 2001). Gates et al. (2003) reviewed pavement marking practices in 19 states and found that even though thermoplastic was used on Portland cement concrete pavements in $37 \%$ of the states, only $16 \%$ of state DOTs considered it to be the best performing material. Some state DOTs have had great success with thermoplastic markings on concrete, while many others 
discontinue its use for concrete pavements. One of the disadvantages of thermoplastic is its color and appearance. Thermoplastic is grayish, making it less visible by day, and has a tendency to crack. Further, the application of thermoplastic marking materials in areas with colder climates is limited due to the poor adhesion of the material to pavement surfaces in lower temperatures. Successful thermoplastic performance on concrete is highly dependent on correct thermoplastic material formulation, proper surface cleaning, moisture removal, and priming (if necessary) before installation. In contrast to the inconsistent performance of thermoplastic markings on concrete pavements in Texas and some other states, the findings of Ahmad et al. (2001) suggested that the bonding strength of thermoplastic markings to concrete pavements was independent of the surface cleaning methods used, and the bonding strengths on both asphalt and concrete pavements were the same for the most part.

4. Tape: Several types of tapes are currently in use, including flat preformed tape and profiled preformed tape. Tapes tend to have a high initial cost and are generally used in areas that require minimal marking and need to perform under severe conditions. Glass beads that provide retroreflectivity in tapes are incorporated into material during factory manufacturing. Freshly installed tape markings typically have initial retroreflectivity values four to six times that of waterborne traffic paints. In a review of studies in several states, Andrady (1997) found evidence from Kentucky and North Carolina that suggested that tapes lose their retroreflectivity rapidly and their useful life may be as little as three years. 
Findings by Lee et al. (1999) also indicated that there was a dramatic drop in retroreflectivity over time. Given the wide variety of tape materials available commercially, it is not surprising that there is such a broad range of estimates for their useful life. However, the consensus is that if applied properly, tape will provide between 4 and 8 years of use. The successful performance on tape depends on many stringent requirements, including proper pavement and air temperature, adequate preparation of the surface (e.g., dry and free of existing markings), the use of quality adhesives (if markings are overlaid), and the need for proper curing time. Nevertheless, according to many agencies, the advantages of using preformed tape appear to outweigh the disadvantages or strict requirements. In fact, permanent preformed tape was most frequently recommended as the marking material with the best long-term performance by 19 state DOTs surveyed (Gates et al., 2003). In general, inlaid markings (where the tape is pressed into the pavement surface while it is still warm) outlast overlaid markings (where tape is adhered to the pavement surface through the use of an adhesive or installed by heat fusion) and both are snowplowable. Tapes are devoid of VOCs but when they are applied as overlaid markings, the VOC content of the adhesive primer or surface preparation adhesive must also be considered.

5. Epoxy: Similar to polyester, polyurea, and methacrylate, epoxy is a type of twocomponent material that is produced on site through the reaction of two separate chemical reactants. Epoxy paint has traditionally been viewed as a marking material that provides exceptional adhesion to both asphalt and concrete 
pavements when the pavement surface is properly cleaned before application (Gate et al., 2003). The strong bond that forms between epoxy paints and both asphalt and concrete pavement surfaces results in the material being highly durable when applied on both pavement surfaces. In addition, epoxy markings have low VOC content, but the chemicals used to produce them are classified as hazardous materials. The first component of the epoxy typically contains resin, pigment, extenders, and fillers, while the second component acts as a catalyst to accelerate setting time. Glass beads are either applied on the surface of the stripe while it is still wet or is pre-mixed into the first component. Although epoxy markings are generally considered to have moderate cost and have a service life of 2 to 4 years, a review of research efforts in Texas and California by Andrady (1997) revealed that epoxy stripes have been shown to discolor with age, particularly when exposed to intense ultraviolet light. Gates et al. (2003) pointed out that another usual complaint with many epoxy materials is the long drying times (sometimes more than 40 minutes) that limit the use of this material under high traffic conditions. Regardless of its shortcomings, a survey conducted by Gates et al. (2003) found that more agencies used epoxy markings on concrete surfaces with high traffic volumes than any other pavement marking material, although the majority of the agencies responding to the survey selected preformed tape as the top performer on concrete.

6. Methyl Methacrylate: Methyl methacrylate is another two-component material with negligible VOC content that is produced onsite through the chemical 
reaction of two separate reactants. The reacting components consist of a pigmented material containing a methyl methacrylate monomer, pigments, fillers, glass beads and silica (as first component), and a liquid or powder catalyst (Migletz \& Graham, 2002). Methacrylate markings are highly durable and can be sprayed or extruded but generally require long no-track times (Andrady, 1997). According to Gates et al. (2003), methyl methacrylate is an attractive pavement marking material because it can be applied in low temperatures, is resistant to oils, anti-freeze, and other chemicals commonly found on roadways, and bonds well to both asphalt and concrete surfaces. A 2002 survey conducted by the researchers revealed that the use of methyl methacrylate pavement markings is still very limited in the United States. Of the 19 state agencies surveyed, only Oregon, Alaska and California used methyl methacrylate pavement markings. All three states rated the material very highly. In California and Alaska, methyl methacrylate pavement markings were found to outperform thermoplastic and paint markings in terms of durability, cost, visibility, and service life when applied in heavy snowfall areas. Based on the information available on this pavement marking material, Gates et al. (2003) suggested that methyl methacrylate pavement markings are particularly suited to cold climates. No evidence was found to support its use in warm-weather climates, especially given the high cost of the material, the slow no-track times, and need for specialized equipment for application. 
7. Polyester: Polyester marking materials are produced onsite through the mixture of two separate groups of reactants (chemicals) immediately before application. Glass beads are dropped onto the surface of the stripe while it is still wet to provide retroreflectivity. Polyester is best used on asphalt pavements and can be applied over existing markings. Although polyester markings have low VOC content, the chemicals used to produce the material are classified as hazardous materials (Andrady, 1997).

8. Polyurea: Polyurea is a two-component material that is produced onsite through the chemical reaction of two separate components. The first component of this material consists of a mixture of resins, pigments, and fillers, while the second component is a cross linker. Glass beads are dropped onto the wet surface to provide retroreflectivity. One manufacturer uses a combination of glass beads and a layer of reflective elements (with microcrystalline, 1.9 refractive index, ceramic beads) to provide a higher level of retroreflectivity (Andrady, 1997). Polyurea is a relatively new pavement marking material that is often marketed by manufacturers as a durable marking material that maintains good color stability when exposed to ultraviolet light, cures quickly (3 to 8 minutes at all temperatures), may be applied at low ambient pavement surface temperatures (as low as $40^{\circ} \mathrm{F}$ ), is not affected by humidity, and works equally well on asphalt and concrete pavements. A survey conducted by Gates et al. (2003) found that 18 of 19 state agencies surveyed cited little experience with the material and that there are limited data on the performance of polyurea markings. Initial findings suggest 
that while the material is highly durable, the durability and abrasion resistance of the ceramic elements that enhance the retroreflectivity of the material is questionable. However, no further literature could be found on the effects and performance of the ceramic elements in polyurea. Gates et al. (2003) indicate that a major disadvantage identified was the need for special equipment and high cost compared to most other marking materials.

\subsection{Durability, Visibility, and Cost of Marking Materials}

In general, pavement marking performance is judged by two criteria: durability and visibility (Migletz, Fish, and Graham, 1994). Durability refers to the amount of material remaining on the pavement surface over time. Durability affects both the daytime and nighttime appearance of markings. Durability performance is often measured either by determining the percentage of material remaining on the surface or by directly testing the bond strength of a material to the surface. Visibility relates to the brightness of the material. Visibility is particularly a nighttime performance measure when the retroreflective properties of the markings greatly influence their ability to be seen. Daytime visibility is related to the contrast of the marking with the pavement surface. Much of the research concerning marking visibility uses retroreflectivity as a proxy measure for visibility performance.

The Virginia Department of Transportation (VDOT) studied the effectiveness of pavement markings (Cottrell and Hanson, 2001). The study examined the durability and 
cost-effectiveness of Virginia's pavement marking materials with consideration of paint contract sizes. VDOT uses various types of material for marking pavements. The three primary types are paint, thermoplastic, and waffle tape (account for $90 \%$ of pavement markings in Virginia). In addition, epoxy and polyurea are also used for pavement markings in Virginia. Cottrell and Hanson (2001) drew the following conclusions on cost-effectiveness:

- The large paint contract is the most cost-effective for two-lane roads under most traffic volume conditions and for four- and six-lane low-volume roads. Polyurea and paint installed under a large-scale contract are the most cost-effective for high-volume four-lane roads, and polyurea and waffle tape are the most costeffective for high-volume six-lane roads.

- For durable markings, the order from most to least cost-effective is polyurea, thermoplastic, epoxy, and waffle tape for the low-volume roads. For higher volume roads, the order is polyurea, waffle tape, thermoplastic, and epoxy. When only the annualized installation costs are considered for a study period of 6 years, the order from least to most expensive is thermoplastic, epoxy, polyurea, and waffle tape. 
Table 1. Pavement Marking Material Service Lives and Installation Costs ( $\$ / \mathrm{mi} / \mathrm{yr})$ (Cottrell and Hanson, 2001)

\begin{tabular}{|c|c|c|c|c|}
\hline Marking Material & Service Life & $\begin{array}{l}2 \text { Lanes on 4-Lane } \\
\text { Divided Highway }\end{array}$ & $\begin{array}{l}3 \text { Lanes on 6-Lane } \\
\text { Divided Highway }\end{array}$ & $\begin{array}{l}2 \text { Lanes on } \\
\text { 2-Lane Highway }\end{array}$ \\
\hline Paint (large contract) & $1 \mathrm{yr}$ & 472 & 524 & 840 \\
\hline Paint (large contract) & $6 \mathrm{mo}$ & 944 & 1,048 & 1,680 \\
\hline Paint (VDOT) & $1 \mathrm{yr}$ & 944 & 1,048 & 1,680 \\
\hline Thermoplastic & $3 \mathrm{yr}$ & 1,377 & 1,528 & 2,800 \\
\hline Epoxy & $3 \mathrm{yr}$ & 1,573 & 1,747 & 3,150 \\
\hline Paint (small contract) & $1 \mathrm{yr}$ & 1,770 & 1,965 & 2,450 \\
\hline Paint (VDOT) & $6 \mathrm{mo}$ & 1,888 & 2,096 & 3,360 \\
\hline Polvurea & $3 \mathrm{yr}$ & 2.753 & 3.057 & 4.900 \\
\hline Paint (small contract) & $6 \mathrm{mo}$ & 3,540 & 3,930 & 4,900 \\
\hline Waffle Tape & $6 \mathrm{yr}$ & 3,540 & 3,930 & 6,300 \\
\hline
\end{tabular}

$1 \mathrm{mi}=1.6 \mathrm{~km}$.

Table 2. Total Cost (\$/mi) of Pavement Marking Materials for Different Study Periods (Cottrell and Hanson, 2001)

\begin{tabular}{llllllll}
\hline Marking Material & Service Life & $\mathbf{1 ~ Y r}$ & $\mathbf{2 ~ Y r}$ & $\mathbf{3 ~ Y r}$ & $\mathbf{4 ~ Y r}$ & $\mathbf{5 ~ Y r}$ & $\mathbf{6} \mathbf{~ Y r}$ \\
\hline Paint (large contract) & $1 \mathrm{yr}$ & 472 & 944 & 1,416 & 1,888 & 2,360 & 2,832 \\
Paint (large contract) & $6 \mathrm{mo}$ & 944 & 1,888 & 2,832 & 3,776 & 4,720 & 5,664 \\
Paint (VDOT) & $1 \mathrm{yr}$ & 944 & 1,888 & 2,832 & 3,776 & 4,720 & 5,664 \\
Thermoplastic & $3 \mathrm{yr}$ & 4,131 & 4,131 & 4,131 & 8,262 & 8,262 & 8,262 \\
Epoxy & $3 \mathrm{yr}$ & 4,719 & 4,719 & 4,719 & 9,438 & 9,438 & 9,438 \\
Paint (small contract) & $1 \mathrm{yr}$ & 1,770 & 3,540 & 5,310 & 7,080 & 8,850 & 10,620 \\
Paint (VDOT) & $6 \mathrm{mo}$ & 1,888 & 3,776 & 5,664 & 7,552 & 9,440 & 11,328 \\
Polyurea & $3 \mathrm{yr}$ & 8,259 & 8,259 & 8,259 & 16,518 & 16,518 & 16,518 \\
Paint (small contract) & $6 \mathrm{mo}$ & 3,540 & 7,080 & 10,620 & 14,160 & 17,700 & 21,240 \\
Waffle Tape & $6 \mathrm{yr}$ & 21,240 & 21,240 & 21,240 & 21,240 & 21,240 & 21,240 \\
\hline
\end{tabular}

$1 \mathrm{mi}=1.6 \mathrm{~km}$.

The Federal Highway Administration (FHWA) sponsored TRB to evaluate the service life of durable, longer lasting pavement markings (Migletz, Graham, \& Bauer, 2001). The study used the cumulative traffic passages (CTP) and the number of months required for the retroreflectivity to drop below a minimum threshold value, which indicated the marking needed to be replaced or restored. The durable pavement markings evaluated in the TRB sponsored study consist of epoxy, poly methyl methacrylate, polyester, thermoplastic, and preformed tape. Measurements of the retroreflectivity of 
the materials were made at six-month intervals during a four-year period with two Laserlux 30 m mobile retroreflectometers provided by the FHWA. In order to measure the service life, threshold retroreflectivity values were used to define the end of a pavement marking service life. Since there are no established criteria for minimum $\mathrm{R}_{\mathrm{L}}$ values, the threshold values shown in Table 3 were established.

Table 3. Threshold Retroreflectivity Values Used to Define the End of Pavement Marking Service Life (Migletz, Graham, \& Bauer, 2001)

\begin{tabular}{lccc}
\hline \multirow{2}{*}{ Color of Marking } & \multicolumn{3}{c}{ Threshold Retroreflectivity Values (mcd/ $\mathbf{m} / \mathbf{l u x})$} \\
\cline { 2 - 4 } & $\begin{array}{c}\text { Non-Freeway } \\
\mathbf{5 6 4} \mathbf{~ k m} / \mathbf{h r}\end{array}$ & $\begin{array}{c}\text { Non-Freeway } \\
\mathbf{2 7 2} \mathbf{~ k m} / \mathbf{h r}\end{array}$ & $\begin{array}{c}\text { Freeway } \\
\mathbf{8} \mathbf{8 9} \mathbf{~ k m} / \mathbf{h r}\end{array}$ \\
\hline White & 85 & 100 & 150 \\
White with RRPMs and/or lighting & 30 & 35 & 70 \\
Yellow & 55 & 65 & 100 \\
Yellow with RRPMs and/or lighting & 30 & 35 & 70 \\
\hline
\end{tabular}

Statistical modeling was used to determine the relationship between decreasing $\mathrm{R}_{\mathrm{L}}$ values with time (in months) and cumulative traffic passages (CTP). CTP values were calculated with the reported average daily traffic (ADT). Tables 4 and 5 list the estimated service lives in terms of roadway type, pavement marking material, and color of line. 
Table 4. Estimated Service Life of Yellow Lines by Roadway Type and Pavement Marking Material (Migletz, Graham, \& Bauer, 2001)

\begin{tabular}{lccc}
\hline & Number of & \multicolumn{2}{c}{ Service Life } \\
\cline { 3 - 4 } Roadway Type and Material & $\begin{array}{c}\text { Pavement } \\
\text { Marking Lines }\end{array}$ & $\begin{array}{c}\text { Average CTP } \\
\text { (million } \\
\text { vehicles) }\end{array}$ & $\begin{array}{c}\text { Elapsed } \\
\text { Months }\end{array}$ \\
\hline Freeway: & 1 & 11.1 & 39.7 \\
Polyester & 3 & 6.9 & 25.8 \\
Profiled tape & 7 & 6.1 & 24.7 \\
Thermoplastic & 4 & 5.3 & 23.5 \\
Profiled thermoplastic & 7 & 4.7 & 23.2 \\
Epoxy & 3 & 6.2 & 21.1 \\
Profiled poly methyl methacrylate & 3 & 3.0 & 15.6 \\
Poly methyl methacrylate & & & \\
Non-Freeway $\leq 64 \mathrm{~km} / \mathrm{hr}:$ & 1 & 11.4 & 50.7 \\
Profiled thermoplastic & 2 & 3.6 & 43.9 \\
Epoxy & 1 & 4.7 & 39.6 \\
Profiled polyester & 1 & 3.5 & 19.6 \\
Profiled tape & & & \\
Non-Freeway $\geq 72 \mathrm{~km} / \mathrm{hr}:$ & 1 & 9.1 & 47.9 \\
Polyester & 6 & 8.9 & 44.1 \\
Epoxy & 3 & 5.1 & 38.9 \\
Profiled tape & 3 & 4.5 & 33.8 \\
Thermoplastic & 2 & 6.5 & 31.0 \\
Profiled poly methyl methacrylate & 3 & 3.9 & 23.0 \\
Profiled thermoplastic & 1 & 4.8 & 20.5 \\
Poly methyl methacrylate & & &
\end{tabular}


Table 5. Estimated Service Life of White Lines by Roadway Type and Pavement Marking Material (Migletz, Graham, \& Bauer, 2001)

\begin{tabular}{lccc}
\hline & Number of & \multicolumn{2}{c}{ Service Life } \\
\cline { 4 - 5 } Roadway Type and Material & $\begin{array}{c}\text { Pavement } \\
\text { Marking Lines }\end{array}$ & $\begin{array}{c}\text { Average CTP } \\
\text { (million } \\
\text { vehicles) }\end{array}$ & $\begin{array}{c}\text { Elapsed } \\
\text { Months }\end{array}$ \\
\hline Freeway: & & & \\
Thermoplastic & 14 & 7.5 & 22.6 \\
Polyester & 2 & 9.6 & 20.8 \\
Profiled tape & 5 & 6.3 & 19.6 \\
Profiled thermoplastic & 7 & 7.5 & 18.4 \\
Profiled poly methyl methacrylate & 6 & 2.4 & 14.0 \\
Epoxy & 11 & 3.7 & 12.8 \\
Poly methyl methacrylate & 6 & 3.7 & 1.9 \\
Waterborne paint & 3 & & \\
\hline Non-Freeway $\leq 64 \mathrm{~km} / \mathrm{hr}:$ & & 25.1 & 55.7 \\
Profiled thermoplastic & 1 & 10.9 & 45.9 \\
Profiled polyester & 2 & 7.5 & 39.4 \\
Epoxy & 2 & 8.8 & 26.9 \\
Profiled tape & & 5.3 & 38.8 \\
\hline Non-Freeway $\geq 72 \mathrm{~km} / \mathrm{hr}:$ & 5 & 6.0 & 36.3 \\
Epoxy & 4 & 8.8 & 34.8 \\
Profiled tape & 5 & 3.4 & 29.3 \\
Thermoplastic & 3 & 2.7 & 27.4 \\
Profiled poly methyl methacrylate & 1 & 3.7 & 24.9 \\
Poly methyl methacrylate & 3 & & \\
Polyester & 6 & &
\end{tabular}

A Minnesota study (Montebello \& Schroeder 2000) was performed to provide guidelines for pavement markings in county and city highways. The study noted that:

1. The formula for alkyd paints has been changed to comply with the new environmental rules. The new formula does not contain high levels of volatile organic compounds (VOC); however, it is highly flammable and presents storage problems. The advantage of this material is that it can be used in cold weather, compared to latex, which should not be used below $50{ }^{\circ} \mathrm{F}$. It is likely that this product will only be used for cold weather application due to its flammability. 
2. For roadways with high AADT (10,000 or more), a more durable product may be a better alternative than paint because it can reduce worker exposure to traffic and maintain a visible line for at least one to four years.

3. Bead application plays an important role in the retroreflectivity of all pavement marking materials. Proper application can lead to increased nighttime visibility and greater line durability.

The Minnesota study recommended the following pavement marking management practices and summarized the findings in Table 6:

- When hiring a striping contractor, consider providing an option for allowing adjacent communities to be included. In some instances, increasing volumes will lower overall costs.

- If painting is necessary in cooler weather, make sure that contracts allow for the use of Mn/DOT approved low-volume VOC-compliant alkyd paints. Because of Minnesota's cold climate and limited construction season, specifications should be written to allow the use of approved alkyd paint as a substitute for latex paint when pavement temperatures are below $50^{\circ} \mathrm{F}$. Communities indicated that lines applied using latex paints on cold pavements are not as durable.

- The cost of applying striping materials is directly related to the quantities, traffic control, material cost and mobilization to and from the job site. The more work that is planned/coordinated to increase quantities and efficiencies, the more costeffective the project will be. 
- If a non-conventional marking material is being considered, the condition of the road must be carefully evaluated to make sure maintenance or other activities will not shorten the life of the pavement marking investment. Also investigate any special mobilization costs for low quantities of specialized materials. When a road is new or has higher traffic volumes, a more durable material could be more costeffective. Mn/DOT uses durable products on the roadways it maintains in the Twin Cities metropolitan area due to the large volumes of traffic.

- Pre-mix paint is a good choice if conventional paint is the desired marking material. Pre-mix already has half of the reflective beads in the paint. Beads in the paint, as well as beads dropped on the surface, lead to good retroreflectivity of the line as it wears. If all of the beads are on the surface of the painted line (which can occur if beads dropped on top of the paint are not applied properly), the top surface of beads will wear off over time. The line may be visible during the day but not at night.

- Match materials to traffic patterns. Conventional materials (paint) can provide up to three years of life on low-volume roads; however, they provide less than a year's worth of life on high-volume roads (roads with an AADT of 10,000 or more). In high-volume areas or in areas that have significant turning movements, consider durable materials such as epoxies, tapes and preformed thermoplastics. Areas in which large quantities of abrasive materials (sand) are applied during winter months may also warrant the use of durable materials.

- Traffic control is important. While most materials dry relatively quickly, workers and drivers are still exposed to traffic during this time. Proper coning and traffic 
control help ensure that the marking material stays on the road and workers have a safer environment to perform their work.

- Consider the use of temporary tape for construction zones. This material is more expensive than the conventional materials, but it is easily removed when the construction job is completed.

- Lane marking materials should be applied just off of the crown. This reduces the direct impact that snowplows have on markings.

- If an organization does its own striping, significant consideration should be given to storage and cleanup requirements. Hazardous materials are costly to dispose of and require more specialized training for personnel.

- Before applying any pavement marking material, refer to the Manual on Uniform Traffic Control Devices for appropriate sizing, location and coloring.

- Prepare the road for the marking application. All road surfaces should be clear of debris before the marking material is applied.

- Apply materials according to the manufacturer's directions. Failure to do so may result in poor quality. 
Table 6. Matrix Of Materials (Montebello \& Schroeder 2000)

\begin{tabular}{|c|c|c|c|c|c|c|}
\hline & $\begin{array}{c}\text { Estimated } \\
\text { Cost Per } \\
\text { Linear Foot }^{(2)}\end{array}$ & $\begin{array}{c}\text { Estimated Life } \\
\text { of the } \\
\text { Product }^{(3)}\end{array}$ & $\begin{array}{l}\text { Application } \\
\text { Temperature }\end{array}$ & $\begin{array}{c}\text { Initial } \\
\text { Retroreflectivity }^{(5)}\end{array}$ & Advantages & Disadvantages \\
\hline \multicolumn{7}{|l|}{ Conventional Products $^{(1)}$} \\
\hline Latex & $\$ 0.03-\$ 0.05$ & $9-36$ months & $\begin{array}{l}\text { Air and pavement } \\
\text { temperature of } 50^{\circ} \mathrm{F} \\
\text { and rising }\end{array}$ & $\begin{array}{l}-275 \text { for white }-180 \\
\text { for yellow with } \\
8 \text { pounds of beads } \\
\text { per gallon of paint }\end{array}$ & $\begin{array}{l}\text { - Inexpensive } \\
\text { - Quick-drying } \\
\text { - Longer life on low-volume roads } \\
\text { - Easy clean-up and disposal } \\
\text { - No collection of hazardous } \\
\text { waste products }\end{array}$ & $\begin{array}{l}\text { - Short life on high-volume roads } \\
\text { - Subject to damage from } \\
\text { sands/abrasives } \\
\text { - Bead application required } \\
\text { - Does not adhere as well to concrete } \\
\text { - Pavement must be warm or it will } \\
\text { not adhere }\end{array}$ \\
\hline Alkyd - New Formula & $\$ 0.03-\$ 0.05$ & $9-36$ months & $\begin{array}{l}\text { Air and pavement } \\
\text { temperature of } 32^{\circ} \mathrm{F}\end{array}$ & \begin{tabular}{|c|}
-275 for white -180 \\
for yellow with \\
8 pounds of beads \\
per gallon of paint
\end{tabular} & $\begin{array}{l}\text { - Inexpensive } \\
\text { - Quick-drying } \\
\text { - Longer-life on low volume roads } \\
\text { - Works in cold temperatures }\end{array}$ & $\begin{array}{l}\text { - Short life on high-volume roads } \\
\text { - Subject to damage from } \\
\text { sands/abrasives } \\
\text { - Bead application required } \\
\text { - Does not adhere as well to concrete } \\
\text { - Is highly flammable and requires } \\
\text { the use of solvents for clean-up } \\
\text { - Has a bad smell }\end{array}$ \\
\hline \multicolumn{7}{|l|}{ Durable Products } \\
\hline Mid-durable Paint & $\$ 0.08-\$ 0.10$ & $9-36$ months $^{(4)}$ & $\begin{array}{l}\text { Air and pavement } \\
\text { temperature of } 50^{\circ} \mathrm{F} \\
\text { and rising }\end{array}$ & $\begin{array}{l}-275 \text { for white }-180 \\
\text { for yellow with } \\
8 \text { pounds of beads } \\
\text { per gallon of paint }\end{array}$ & $\begin{array}{l}\text { - Inexpensive } \\
\text { - Quick-drying } \\
\text { - Longer life on low-volume roads } \\
\text { - Easy clean-up and disposal } \\
\text { - No collection of hazardous } \\
\text { waste products }\end{array}$ & $\begin{array}{l}\text { - Short life on high-volume roads } \\
\text { - Subject to damage from } \\
\text { sands/abrasives } \\
\text { - Bead application required } \\
\text { - Does not adhere as well to concrete } \\
\text { - Pavement must be warm or it will } \\
\text { not adhere }\end{array}$ \\
\hline Epoxy & $\$ 0.20-\$ 0.30$ & 4 years & $\begin{array}{l}\text { Air and pavement } \\
\text { temperature of } 50^{\circ} \mathrm{F} \\
\text { and rising }\end{array}$ & \begin{tabular}{|c}
-300 for white -200 \\
for yellow with \\
25 pounds of beads \\
per gallon of epoxy
\end{tabular} & $\begin{array}{l}\text { - Longer life on low- and high- } \\
\text { volume roads } \\
\text { - More retroreflective }\end{array}$ & $\begin{array}{l}\text { - Slow-drying } \\
\text { - Requires coning and/or flagging } \\
\text { during application } \\
\text { - Heavy bead application required - } \\
\text { may need to be cleaned off of } \\
\text { roadway } \\
\text { - High initial expense } \\
\text { - Subject to damage from } \\
\text { sands/abrasives }\end{array}$ \\
\hline
\end{tabular}


Table 6 (Continued)

\begin{tabular}{|c|c|c|c|c|c|c|}
\hline & $\begin{array}{c}\text { Estimated } \\
\text { Cost Per } \\
\text { Linear Foot }^{(2)}\end{array}$ & $\begin{array}{c}\text { Estimated Life } \\
\text { of the } \\
\text { Product }^{(3)}\end{array}$ & $\begin{array}{l}\text { Application } \\
\text { Temperature }\end{array}$ & $\begin{array}{c}\text { Initial } \\
\text { Retroreflectivity }^{(5)}\end{array}$ & Advantages & Disadvantages \\
\hline Tape & $\$ 1.50-\$ 2.65$ & $4-8$ years & $\begin{array}{l}\text { Inlaid in fresh } \\
\text { bituminous that is } \\
120^{\circ}-150^{\circ} \mathrm{F} \\
\text { Overlaid in an air } \\
\text { temperature of at least } \\
60^{\circ} \mathrm{F} \text { and a pavement } \\
\text { temperature of } 70^{\circ} \mathrm{F}\end{array}$ & $\begin{array}{l}-350 \text { for white }-250 \\
\text { for yellow }\end{array}$ & $\begin{array}{l}\text { - Highly retroreflective } \\
\text { - Long life on low- and high- } \\
\text { volume roads } \\
\text { - Useful in high traffic areas } \\
\text { where wheels cross the marking } \\
\text { - No beads needed } \\
\text { - Reduces worker exposure to } \\
\text { road hazards because of long life }\end{array}$ & $\begin{array}{l}\text { - High initial expense } \\
\text { - Best when used on newly surfaced } \\
\text { roads - probably not worth the } \\
\text { expense for older roads in poor } \\
\text { condition } \\
\text { - May suffer snowplow damage }\end{array}$ \\
\hline Preformed Thermoplastic & NA & $3-6$ years & All temperatures & $\begin{array}{l}\text { - } 275 \text { for white }-180 \\
\text { for yellow }\end{array}$ & $\begin{array}{l}\text { - Long life on low- and high- } \\
\text { volume roads } \\
\text { - Retroreflective } \\
\text { - No beads needed } \\
\text { - Any temperature for application }\end{array}$ & $\begin{array}{l}\text { - Only used for symbols - not used } \\
\text { for edge lines, centerlines or skip } \\
\text { lines } \\
\text { - Subject to damage from } \\
\text { sands/abrasives } \\
\text { - May suffer snowplow damage }\end{array}$ \\
\hline \multicolumn{7}{|l|}{ Temporary Products } \\
\hline Temporary Tape & $\$ 1.10-\$ 1.50$ & $\begin{array}{l}\text { Length of } \\
\text { construction }\end{array}$ & $\begin{array}{l}\text { Air and pavement } \\
\text { temperature of } 35^{\circ} \mathrm{F} \\
\text { and rising }\end{array}$ & $\begin{array}{l}\text { - At least } 275 \text { for } \\
\text { white }-180 \text { for } \\
\text { yellow }\end{array}$ & $\begin{array}{l}\text { - Does not damage new pavement } \\
\text { - Lasts the life of the construction } \\
\text { - Easily applied and removed }\end{array}$ & - Only for use in construction zones \\
\hline
\end{tabular}

(1) Conventional products are available in a pre-mix form. The pre-mix has half of the beads already in the paint. This makes the application easier and enables more of the dropped on beads to adhere to the paint. The pre-mix gives the user higher retroreflectivity for a longer period of time

(2) Price estimates are for a minimum of 20,000 linear feet; lower quantities will result in higher prices. Prices are in 1999 dollars.

(3) Life of the pavement marking material will depend upon road volumes, the amount of sand used in winter, application and road condition.

(4) Life of mid-durable paint has not been thoroughly field tested because it is a new product. The manufacturers of the product claim that it has an enhanced life over other latex paints. In areas where latex may last only a season, the user might get two seasons. In areas where latex lasts longer than a single season the user may get additional seasons out of the mid-durable.

(5) All numbers are measured in $\mathrm{mcd} / \mathrm{m}^{2} / \mathrm{lux}$. 
Pavement marking materials do not bond as strongly on Portland Cement Concrete (PCC) pavements as on asphalt pavements. Pavement marking materials often experience premature de-bonding on concrete roadways. Gates, Hawkins, and Rose (2003) conducted a study to determine the durability of various pavement materials on concrete pavements in Taxes. Their evaluation results for marking materials on concrete pavements are summarized in Table 7.

Table 7. Summary of Attributes for Marking Materials on Concrete Pavements (Gates, Hawkins, and Rose, 2003)

\begin{tabular}{|c|c|c|}
\hline Marking Material & Advantages & Disadvantages \\
\hline TxDOT Thermoplastic ${ }^{\mathrm{a}}$ & $\begin{array}{l}\text { Low initial cost; availability of materials } \\
\text { and contractors }\end{array}$ & $\begin{array}{l}\text { May not bond well to concrete without } \\
\text { suitable primer/sealer }\end{array}$ \\
\hline $\begin{array}{l}\text { Concrete } \\
\text { Thermoplastic }^{\mathrm{b}}\end{array}$ & $\begin{array}{l}\text { Improved durability on concrete vs. } \\
\text { standard TxDOT thermoplastic }\end{array}$ & $\begin{array}{c}\text { Slightly more expensive than TxDOT } \\
\text { standard thermoplastic; relatively little } \\
\text { use in Texas }\end{array}$ \\
\hline Epoxy & Very good durability on concrete & $\begin{array}{l}\text { Slightly more expensive than TxDOT } \\
\text { standard thermoplastic; some epoxies are } \\
\text { susceptible to fading under intense } \\
\text { sunlight }\end{array}$ \\
\hline Preformed Tape & $\begin{array}{l}\text { Superior durability on concrete; most tape } \\
\text { products are warranted by manufacturer }\end{array}$ & $\begin{array}{l}\text { High initial cost; strict application } \\
\text { requirements }\end{array}$ \\
\hline Polyurea & Very good durability on concrete & $\begin{array}{l}\text { Moderately high initial cost; may require } \\
\text { specialized equipment to apply (depends } \\
\text { on resin/catalyst ratio) }\end{array}$ \\
\hline Methyl Methacrylate & $\begin{array}{l}\text { Good durability on concrete; may be } \\
\text { applied at cold temperatures }\end{array}$ & Very little use nationwide \\
\hline Modified Urethane & $\begin{array}{l}\text { Very good durability on concrete; may be } \\
\text { placed with standard epoxy equipment }\end{array}$ & Very little use nationwide \\
\hline Waterborne Paints & Very low initial cost & Short service life \\
\hline Ceramic Buttons & $\begin{array}{l}\text { Good durability on concrete; availability } \\
\text { of materials and contractors }\end{array}$ & Provide no retroreflectivity \\
\hline
\end{tabular}

Based on the evaluation results, Gates, Hawkins, and Rose (2003) made recommendations on using marking materials on concrete pavements in Taxes in terms of traffic volume and remaining pavement service life, as shown in Tables 8 and 9. 
Table 8. Recommended Pavement Marking Materials for Concrete Pavements (Gates, Hawkins, and Rose, 2003)

\begin{tabular}{|c||c|c|c||}
\hline \multicolumn{1}{||c||}{ Traffic Characteristic $^{\mathrm{a}}$} & \multicolumn{2}{c||}{ Pavement Remaining Service Life } \\
\cline { 2 - 4 } & 0-2 Years & $\mathbf{2 - 4}$ Years & \multicolumn{1}{|c}{ Years } \\
\hline \hline$A A D T<10,000$ & TxDOT Thermo & Epoxy & Epoxy \\
\hline $10,000<A A D T<50,000$ & TxDOT Thermo ${ }^{\mathrm{b}}$ & Epoxy & Epoxy \\
\hline$A A D T>50,000$ & Epoxy & Epoxy & Preformed Tape \\
\hline Commercial Vehicles or Heavy Weaving/Turning & Epoxy & Preformed Tape & Preformed Tape \\
\hline \hline
\end{tabular}

Notes: Contrast markings or profiled markings may be used to improve visibility and safety as needed.

${ }^{\text {a }} \mathrm{AADT}=$ Average Annual Daily Traffic.

${ }^{\mathrm{b}}$ Primer/sealer required prior to application of current TxDOT spec. thermoplastic on bare concrete.

Table 9. Alternative Pavement Marking Materials for Concrete Pavements (Gates, Hawkins, and Rose, 2003)

\begin{tabular}{|c|c|c|c|}
\hline \multirow{2}{*}{ Traffic Characteristic $^{a}$} & \multicolumn{3}{|c|}{ Pavement Remaining Service Life } \\
\hline & 0-2 Years & $2-4$ Years & $>4$ Years \\
\hline$A A D T<10,000$ & $\begin{array}{c}\text { Epoxy, Water-Based } \\
\text { Paint }\end{array}$ & $\begin{array}{l}\text { Thermo }^{\mathrm{b}} \text { (concrete } \\
\text { formulation), Modified } \\
\text { Urethane, Water-Based } \\
\text { Paint, Polyurea, MMA }\end{array}$ & $\begin{array}{c}\text { Thermo }^{\mathrm{b}} \text { (concrete } \\
\text { formulation), Modified } \\
\text { Urethane, Polyurea, } \\
\text { Water-Based Paint, } \\
\text { MMA }\end{array}$ \\
\hline $10,000<A A D T<50,000$ & $\begin{array}{c}\text { Epoxy, Modified } \\
\text { Urethane, Water-Based } \\
\text { Paint }\end{array}$ & $\begin{array}{c}\text { Thermo }^{b} \text { (concrete } \\
\text { formulation), Modified } \\
\text { Urethane, Polyurea, } \\
\text { Water-Based Paint, } \\
\text { MMA }\end{array}$ & $\begin{array}{c}\text { Thermo }^{\mathrm{b}} \text { (concrete } \\
\text { formulation), Preformed } \\
\text { Tape, Polyurea, } \\
\text { Modified Urethane, } \\
\text { MMA }\end{array}$ \\
\hline$A A D T>50,000$ & $\begin{array}{l}\text { Thermo }^{\mathrm{b}} \text { (concrete } \\
\text { formulation), Modified } \\
\text { Urethane, Polyurea }\end{array}$ & $\begin{array}{c}\text { Thermo }^{\mathrm{b}} \text { (concrete } \\
\text { formulation), Preformed } \\
\text { Tape, Polyurea, } \\
\text { Modified Urethane, } \\
\text { MMA }\end{array}$ & $\begin{array}{l}\text { Epoxy, Thermo } \\
\text { (concrete formulation), } \\
\text { Polyurea, Modified } \\
\text { Urethane, MMA }\end{array}$ \\
\hline $\begin{array}{l}\text { Commercial Vehicles or } \\
\text { Heavy Weaving/Turning }\end{array}$ & $\begin{array}{l}\text { Thermo }^{\mathrm{b}} \text { (concrete } \\
\text { formulation), Modified } \\
\text { Urethane, Polyurea }\end{array}$ & $\begin{array}{l}\text { Epoxy, Thermo }^{\mathrm{b}} \\
\text { (concrete formulation), } \\
\text { Polyurea, Modified } \\
\text { Urethane, MMA }\end{array}$ & $\begin{array}{c}\text { Epoxy, Thermo }^{\mathrm{b}} \\
\text { (concrete formulation), } \\
\text { Polyurea, Modified } \\
\text { Urethane, MMA }\end{array}$ \\
\hline
\end{tabular}

Notes: Marking materials listed in order of recommendation, with the highest alternative recommendation listed first.

Contrast markings or profiled markings may be used to improve visibility and safety as needed.

${ }^{a} \mathrm{AADT}=$ Average Annual Daily Traffic.

'Please see manufacturer's recommendations for use of primer/sealer prior to thermoplastic application.

As indicated in Tables 8 and 9, the researchers recommended that epoxy materials and preformed tapes be used for pavement markings on PCC roadways and that TxDOT specification thermoplastic only be used for short-term applications with low to medium traffic. 
Missouri DOT's District 7 conducted a study to develop a pavement marking management system to address the issues of quality control and quality assurance (Weinkein, Branham, and Ginder, 2002). As part of the study, District 7 of Missouri DOT evaluated several pavement marking materials. The evaluation yielded some interesting results. The study compared the effects of the large beads (Type L) and small beads (Type 1) in waterborne paints on pavement marking retroreflectivity to see if use of large beads is worth the increased. Visibeads are Type L beads provided by Potters Industries. The costs in 2001 of the beads are shown below (Weinkein, Branham, and Ginder, 2002):

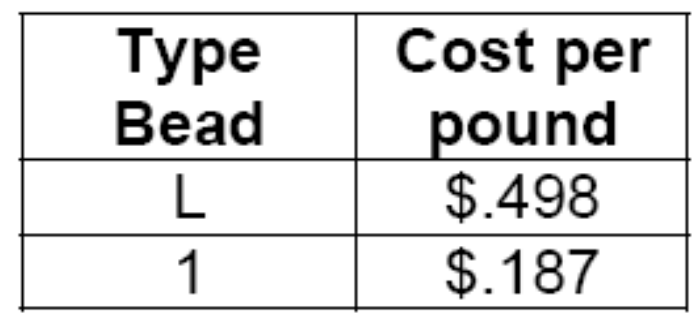

In the Missouri study, only yellow markings were analyzed. After one winter season, $54 \%$ of the markings with Visibeads had retroreflectivity values above $200 \mathrm{mcd} / \mathrm{m}^{2} / \mathrm{lux}$, compared to $12 \%$ with standard beads. $12 \%$ of the Visibeads markings fell below 120 $200 \mathrm{mcd} / \mathrm{m}^{2} / \mathrm{lux}$ as compared with $22 \%$ of markings with standard beads. The Missouri report indicates that a North Carolina study had similar results. That is, using large beads in waterborne paints would improve the performance of pavement markings. The retroreflectivity values for large and small beads on the testing sections in Missouri are listed in Table 10. 
Table 10. Retroreflectivity Values of Waterborne Paint Pavement Markings with Large and Small Beads (Weinkein, Branham, and Ginder, 2002)

Newton County, Route 60, Asphaltic Hot Mix, Waterborne Paint, Striped 5/05/99

\begin{tabular}{|l|c|c|c|c|c|c|}
\hline $\begin{array}{c}\text { Beg } \\
\text { Log } \\
\text { Point }\end{array}$ & $\begin{array}{c}\text { End } \\
\text { Log } \\
\text { Point }\end{array}$ & Direction & Line Type & $\begin{array}{c}\text { Type } \\
\text { Bead }\end{array}$ & Date Read & Avg Mcd \\
\hline 0 & 40 & W & CL (yellow) & L & $7-18-1999$ & 246 \\
\hline 60 & 1.00 & W & CL (yellow) & 1 & $7-18-1999$ & 208 \\
\hline
\end{tabular}

Newton County, Route 86, Asphaltic Hot Mix, Waterborne Paint, Striped 5/05/99

\begin{tabular}{|l|l|l|l|l|l|l|}
\hline $\begin{array}{l}\text { Beg } \\
\text { Log } \\
\text { Point }\end{array}$ & $\begin{array}{c}\text { End } \\
\text { Log } \\
\text { Point }\end{array}$ & Direction & Line Type & $\begin{array}{c}\text { Type } \\
\text { Bead }\end{array}$ & Date Read & Avg Mcd \\
\hline 0 & 3.80 & E & REL (white) & L & $7-17-1999$ & $243^{*}$ \\
\hline 0 & 3.80 & W & REL (white) & 1 & $7-17-1999$ & 235 \\
\hline 0 & 3.90 & W & CL (yellow) & L & $7-18-1999$ & 265 \\
\hline 3.90 & 7.30 & W & CL (yellow) & 1 & $7-18-1999$ & 232 \\
\hline 3.90 & 7.30 & W & REL (white) & L & $7-17-1999$ & $203^{\star}$ \\
\hline 3.90 & 7.30 & E & REL (white) & 1 & $7-17-1999$ & 270 \\
\hline
\end{tabular}

*When retroreflectivity readings were taken with a handheld unit, these two lines read $100 \mathrm{mcd}$ brighter in the opposing direction. The Type 1 bead reading did not change with direction. The conclusion must be that the Type L beads were improperly placed, probably due to the striper's speed being too fast.

Weinkein, Branham, and Ginder (2002) believe that the benefit from Type L (large beads) is that they provide better wet nighttime retroreflectivity. An additional benefit with using large beads is the reduction in "paint on vehicle" complaints. The Missouri report indicates that in 2002, Texas and Kansas started using large beads totally for in-house pavement markings. Other state DOT's using durables with large beads were Kansas, New York, New Jersey, Connecticut, Rhode Island, Pennsylvania, Utah, Nevada, Illinois, Nebraska, Oregon. State DOTs using waterborne with large beads included Kansas, Maryland, Ohio Turnpike, Texas, and limited use in New York, Pennsylvania, 
Nevada. The application rate of 12 lbs of large beads per gallon of paint was a manufacturer's recommendation. Missouri DOT’s District 7 did testing in 1996-1997 on the appropriate application rate of large beads. Test stripes with 8 lbs., 10 lbs., and 12 lbs. were placed with 15 mils of paint. The 10 lbs. per gallon of paint provided good wet nighttime retroreflectivity. Missouri DOT planned to do further testing to obtain accurate information on the best combination of beads and paint thickness to yield the best markings for retroreflectivity and durability.

The Missouri study also found that heavier applications of waterborne paints generally increase the retroreflectivity of pavement markings. On average, the retroreflectivity values for two different amounts of paint applications were as follows:

- 18 gals/mile (15 mil) with 10 lbs/gallon of Visibeads: white strip: $243 \mathrm{mcd} / \mathrm{m}^{2} / \mathrm{lux}$; yellow strip: $207 \mathrm{mcd} / \mathrm{m}^{2} / \mathrm{lux}$.

- 20 gals/mile (17 mil) with $12 \mathrm{lbs} /$ gallon of Visibeads: white strip: $350 \mathrm{mcd} / \mathrm{m}^{2} / \mathrm{lux}$; yellow strip: $260 \mathrm{mcd} / \mathrm{m}^{2} / \mathrm{lux}$.

Since 1994, Missouri DOT had been using 14-16 mils of paint with 8 lbs/gallon of Type 1 beads (small). At the beginning of the 2001 striping season, the District 7 started routinely using 23 mils with 12 lbs of large beads per gallon of paint. Generally application rates can be increased with minimal increase in equipment costs and labor. The increased cost to use a different material or increase application rates is predominantly due to increased material costs. The following chart (Table 11) shows 2001 material costs per foot for yellow markings for different application rates and materials in Missouri. 
Table 11. Material Costs of Different Applications

(Weinkein, Branham, and Ginder, 2002)

\begin{tabular}{|l|l|c|c|c|}
\hline Mil & Gal & $\begin{array}{c}\text { Lbs of beads } \\
\text { per gal of paint }\end{array}$ & Bead Type & $\begin{array}{c}\text { Materials Cost } \\
\text { per foot }\end{array}$ \\
\hline 15 & 18 & 8 & 1 & 0.019 \\
\hline 15 & 18 & 10 & 1 & 0.021 \\
\hline 15 & 18 & 10 & L & 0.031 \\
\hline 17 & 20 & 10 & L & 0.035 \\
\hline 20 & 22 & 10 & L & 0.038 \\
\hline 20 & 22 & 12 & L & 0.041 \\
\hline 23 & 25 & 12 & L & 0.045 \\
\hline $23^{*}$ & 25 & 12 & L & 0.056 \\
\hline
\end{tabular}

Based on the evaluation results, the Missouri study provided a list of recommendations as shown below (Weinkein, Branham, and Ginder, 2002). It is believed that the recommendations are useful information for INDOT to consider with respect to pavement markings.

- Yellow markings on lower volume roadways should not be striped every year. This becomes very evident after linking the retroreflectivity data collected in conjunction with the subjective ratings for the markings.

- Roadways that have been chip sealed and/or fog sealed should have a stripe with different mil thickness as opposed to roadways without that type of preventive maintenance. Those roadways that are chip sealed should have a minimum of two applications in the year it is sealed, or increase the mil thickness and bead output.

- The Missouri DOT should consider using more of the higher build products (i.e., HD-21). The test areas where HD-21 was applied consistently performed well even after 2 years of wear.

- Some areas of the interstate and high volume US routes have enormous amounts of paint build up. Those areas with excessive layers of product from continual restriping are not performing as well. These areas are prime candidates for durable markings. One other way to alleviate the build up problem is to re-stripe roadways by tagging skips onto old skips and placing the edge line next to the old edge lines. 
This might not be preferred but gives the driver an eight-inch edge line and a 20foot skip providing more delineation. (However, tagging on lines is not desirable due to the appearance of the stripe it will produce.)

- A predetermined sampling rate for quality control checks should be implemented. The recommended rate is $20 \%$ of the district's pavement markings.

- Pavement markings that have been placed under the construction program are not performing for Missouri DOT's District 7 as well as in-house latex operations. Therefore, it is recommended that the Missouri DOT institute performance specifications for all contracts applied pavement markings irrespective of material type and include those markings in the pavement marking management system.

- The need for the Missouri DOT to develop a new product approval process is essential. In today's changing environment more and more products are coming into the market. Agencies need to evaluate those products without having to pay for them to find out they've failed later on. Products should be worthy enough to stand on their own merits and not rely on DOT's to pay for their lack of product development when they fail.

- Eliminate the procurement of pavement marking materials by the low bid process. If an agency's overall goal is to raise the level of performance and quality of their pavement marking program, than why buy the cheapest product that meets your specifications? The small increase that agency may pay for better products can be recovered many times over in longer lasting materials that don't need to be restriped as often.

- Planning. Develop a decision matrix based on qualitative/quantitative factors including remaining roadway life and preventative maintenance practices for when markings need to be replaced. (Laserlux retroreflectivity readings are critical components in the process.)

- More research is needed in application rates, durability and retroreflectivity and to evaluate the results and findings.

- The need for statewide technical assistance, training, verification of consistent processes and quality assurance for the districts was demonstrated.

- Retroreflectivity readings taken by a Laserlux retroreflectometer are needed on inhouse markings of a sufficient size sample for quality assurance.

- Funding needs to be set up for readings to be taken with a Laserlux mobile retroreflectometer.

- Missouri DOT should start using paint with $4^{\text {th }}$ generation resins. Paint with these resins has generally been accepted nation wide.

- Missouri DOT needs to change its emphasis from quantity to quality for in-house pavement markings.

- New pavement surfaces should receive a heavier one-time application of material or be striped twice in a season. Application rates should be based on the porosity of the surface.

- Missouri DOT needs to set general criteria for second and third stripe. If a section of road does not hold a stripe through the winter, other measures should be taken. District 7 has found 3M-380 contrast tape to be a good solution. 
- In-house pavement markings outperformed contractor applied markings in District 7. Efforts need to continue to improve contractor applied pavement markings.

- The commitment needs to be made and a program implemented that ensures durable markings are maintained as durables and not just "forgotten" about and striped over with waterborne paint. A set system of roads needs to be selected to be maintained with durable markings (epoxy). Funding should be maintained at General Headquarters to routinely "cap" the durable markings and replace the markings as needed.

- The existing financial management system does not provide a method to track and determine the actual cost per foot of in-house pavement markings. This information is critical in order to compare in-house to contractor applied pavement markings (including durables based on life cycle cost). A reasonable practical method must be found. The Pavement Marking Management System will perform this function after a period of information collection and some minor refinement.

- A decision must be made if and what will be implemented from these research projects. Who determines how and what is changed? What changes and improvements are made in processes and materials? If this work is to continue, traffic and maintenance must embrace the program in order for it to continue and expand. General Headquarters must support its expansion. A statewide champion is needed to make it happen. If the information and results from the research projects are not accepted and embraced, the possibility exists that District 7's improvements in quality of pavement markings will be ignored and District 7 will be forced to go back to lower standards.

Costs of various pavement marking materials as used in studies conducted by the Pennsylvania Transportation Institute (PTI) (Lee, et al. 1999) and Michigan State University (Antle, et al. 1990) are listed in Table 12.

Table 12. Pavement Marking Material Costs According to the Pennsylvania Transportation Institute and Michigan State University (Thomas and Schloz (2001)

\begin{tabular}{lcc}
\hline Pavement Marking Material & $\begin{array}{c}\text { PTI Cost per Foot } \\
\mathbf{( \$ / f t})\end{array}$ & $\begin{array}{c}\text { MSU Cost per Foot } \\
\mathbf{( \$ / \mathbf { f t } )}\end{array}$ \\
\hline Solvent-borne paint & 0.03 & 0.03 \\
Waterborne paint & 0.03 & 0.05 \\
Polyester paint & 0.19 & 0.09 \\
Epoxy & 0.23 & $0.25-0.35$ \\
Thermoplastic & 0.31 & 0.45 \\
Tape & 0.89 & $1.50-2.00$ \\
\hline
\end{tabular}




\subsection{Equipment for Measuring the Retroreflectivity of Pavement Markings}

In the Missouri report, Weinkein, Branham, and Ginder (2002) discussed the experience that Missouri DOT had with various types of retroreflectivity measurement equipment. Missouri DOT had utilized the Mirolux 12, Mirolux 30, LTL 2000 and Laserlux retroreflectometer to take retroreflectivity readings. Each of Missouri DOT's 10 districts had a Mirolux 30 unit for use by construction to check retroreflectivity on contractor applied pavement markings. One of the districts had an LTL 2000 unit. Missouri DOT did not own a Laserlux unit, but hired a company to obtain retroreflectivy readings with a Laserlux unit during a study on pavement markings. Since no national calibrated standard for retroreflectivity currently exists in this country, instruments cannot be calibrated to a known, accepted standard, and it is impossible to determine which instrument measures pavement markings most accurately. The Missouri study found that the readings from the various instruments (Mirolux 30, LTL 2000, Laserlux retroreflectometer) do not directly correlate with each other. Care must be used in comparing readings taken by the different instruments. Missouri DOT's experience (Weinkein, Branham, and Ginder, 2002) with the retroreflectivity measurement showed that the Laserlux retroreflectivity readings are more accurate and thorough than the Mirolux 30. The Mirolux handheld unit measures an area 3.5 inches wide and 4 inches long at each set up. The Laserlux mobile unit can take 70,000 measurements per hour at highway speeds and can measure an area of 3.5 feet in width continuously. The instrument projects light onto the markings and then measures the amount of retroreflected light. Using calculated conversions of the information, it aims to replicate a headlight height of .65 of a meter, driver eye height of 1.2 meters and a forward viewing 
point of 30 meters, which is known as 30-meter geometry. Handheld units require workers to be on the roadway to actually take the readings. Normally this must be done under traffic with the use of traffic control, while no special traffic control is needed for the mobile units. Once the proper quality control is used and information collected during the placement of a stripe, the Laserlux is the most effective method to provide quality assurance on the pavement markings. The Missouri study indicates that a retroreflectivity reading above $250 \mathrm{mcd} / \mathrm{m}^{2} / \mathrm{lux}$ for white and above $175 \mathrm{mcd} / \mathrm{m}^{2} / \mathrm{lux}$ for yellow by a Laserlux retroreflectometer on new waterborne paint markings are considered good retroreflectivity.

A study for the Alabama Department of Transportation (Lindly, Yellapu, and Supriyasilp, 2002) performed field-testing and analysis of two competing pavement marking retroreflectometers: the Laserlux and the LTL2000. The Laserlux costs roughly $\$ 200,000$ per unit that takes readings at driving speed and produces computerized output. The handheld LTL2000 device costs approximately $\$ 20,000$ that also provides computerized output. The cost components in 2002 (the time of the study) included the following:

- The equipment cost of a Laserlux retroreflectometer was $\$ 206,000$ including a vehicle and installation. The cost of a vehicle was $\$ 20,000$.

- The equipment cost of a LTL2000 retroreflectometer was $\$ 17,330$.

- The training cost for the Laserlux retroreflectometer was $\$ 9,722$, while no training cost was required for LTL 2000.

The project was conducted to evaluate the relative usefulness and productivity of the two devices. The cost analysis of the two retroreflectometers indicates that the Laserlux would be the more cost effective retroreflectometer when measuring approximately 
11,000 centerline miles (33,000 miles of pavement marking) for an analysis period of eight years. The cost to test pavement marking for those circumstances is estimated approximately $\$ 5 /$ mile of marking per year for the Laserlux and approximately $\$ 35 /$ mile of marking per year for the LTL2000. Only one Laserlux and one crew would be required to perform the testing. Eight LTL2000s and eight crews would be required to perform the same job. The initial capital expense of the LTL2000 is less than that of the Laserlux. However, operational costs per mile are higher for the LTL2000. Thus, as more miles of pavement marking stripe per year are measured, Laserlux becomes more cost efficient. The study determined that the mileage break point was approximately 580 miles of two-lane road system per year. That is, if it is needed to measure more the 580 miles of pavement markings on a two-lane road system per year, the Laserlux would be less costly than the LTL 2000 devices. Thus, for a local highway agency, such as city or county, with less than 550 centerline miles of road to maintain, the LTL2000 may be more cost effective than the Laserlux.

To obtain the current information on prices and services of various types of retroreflectivity measuring devices, the author of this report contacted several vendors. The information on prices and models of various types of devices is given below:

- 71000 StripeMaster Pavement Marking Retroreflectometer: \$14,985

- 75000 Stripemaster II Pavement Marking Retroreflectometer with Internal Printer and GPS: $\$ 17,500$

- 1200F Field Raised Pavement Marker w/ data logger ASTM Geometry (0.2 OBSRV) $\$ 17,500$ 
- Laserlux: \$150,000 to $\$ 180,000$ (including a van, training, and one year parts and labor warranty). (Note: $\$ 180,000$ has additional options, such as 2nd year maintenance, video overlay, etc.)

- LTL-X: \$18,600. 30-meter geometry pavement marking retroreflectometer with integrated GPS, measuring nighttime visibility of pavement markings.

- QD30: \$17,220. Pavement marking daytime reflectometer, measuring daytime brightness (as viewed by driver) of markings and road surfaces. 


\section{CHAPTER 3. THE STATE OF PRACTICE OF PAVEMENT MARKING APPLICATIONS IN INDIANA}

In order to find out the state of practice of using pavement marking materials in Indiana, a questionnaire survey was sent to the six INDOT districts. Only three of the six districts responded to the questionnaire survey. The results of the questionnaire survey are summarized in Table 13 through Table 15.

Table 13. Use of Pavement Marking Materials in Vincennes District

\begin{tabular}{|c|c|c|c|c|c|c|}
\hline \multicolumn{7}{|c|}{ Pavement Materials in Vincennes District } \\
\hline Material & $\begin{array}{c}\text { Cost } \\
(\$ / \text { foot })\end{array}$ & $\begin{array}{l}\text { Service Life } \\
\text { (Year) }\end{array}$ & $\begin{array}{l}\text { Pavement } \\
\text { Types }\end{array}$ & $\begin{array}{l}\text { Marking } \\
\text { Colors }\end{array}$ & Brand/Manufacturer & $\begin{array}{c}\% \\
\text { Usage }\end{array}$ \\
\hline $\begin{array}{l}\text { Waterborne } \\
\text { Paints }\end{array}$ & $\$ 0.5 / \mathrm{ft}$ & 1 & $\begin{array}{l}\text { Asphalt, } \\
\text { Concrete }\end{array}$ & $\begin{array}{l}\text { White, } \\
\text { Yellow }\end{array}$ & Sherwin Williams & 99 \\
\hline Thermoplastic & $\$ 0.2 / \mathrm{ft}$ & 3 to 5 & $\begin{array}{l}\text { Asphalt, } \\
\text { Concrete }\end{array}$ & $\begin{array}{l}\text { White, } \\
\text { Yellow }\end{array}$ & Dobco & 0.5 \\
\hline Epoxy & N/A & 3 & $\begin{array}{l}\text { Asphalt, } \\
\text { Concrete }\end{array}$ & $\begin{array}{l}\text { White, } \\
\text { Yellow }\end{array}$ & N/A, by contractor & 0.5 \\
\hline $\begin{array}{c}\text { Methyl } \\
\text { methacrylate }\end{array}$ & $\begin{array}{l}\text { Not } \\
\text { Used }\end{array}$ & N/A & N/A & N/A & N/A & \\
\hline $\begin{array}{l}\text { Conventional } \\
\text { solvent paints }\end{array}$ & $\begin{array}{c}\text { Not } \\
\text { Used }\end{array}$ & N/A & N/A & N/A & N/A & \\
\hline Polyester & $\begin{array}{l}\text { Not } \\
\text { Used }\end{array}$ & N/A & N/A & N/A & N/A & \\
\hline Polyurea & $\begin{array}{l}\text { Not } \\
\text { Used }\end{array}$ & N/A & N/A & N/A & N/A & \\
\hline $\begin{array}{l}\text { Preformed } \\
\text { tapes }\end{array}$ & N/A & 1 to 5 & $\begin{array}{l}\text { Asphalt, } \\
\text { Concrete }\end{array}$ & $\begin{array}{l}\text { White, } \\
\text { Yellow }\end{array}$ & $\begin{array}{l}\text { Pave-Mark, Flex-o- } \\
\text { Lite, 3-M }\end{array}$ & \\
\hline
\end{tabular}


Table 14. Use of Pavement Marking Materials in Fort Wayne District

\begin{tabular}{|c|c|c|c|c|c|c|}
\hline \multicolumn{7}{|c|}{ Pavement Materials in Fort Wayne District } \\
\hline Material & $\begin{array}{c}\text { Cost } \\
\text { (\$/foot) }\end{array}$ & $\begin{array}{c}\text { Service Life } \\
\text { (Year) }\end{array}$ & $\begin{array}{l}\text { Pavement } \\
\text { Types }\end{array}$ & $\begin{array}{c}\text { Marking } \\
\text { Colors }\end{array}$ & Brand/Manufacturer & $\begin{array}{c}\% \\
\text { Usage }\end{array}$ \\
\hline $\begin{array}{l}\text { Waterborne } \\
\text { Paints }\end{array}$ & $\begin{array}{c}\$ 0.2 \text { to } \\
\$ 0.5 / \mathrm{ft} \text { by } \\
\text { contract; }< \\
0.5 \text { by } \\
\text { INDOT }\end{array}$ & 1 & Asphalt & $\begin{array}{l}\text { White, } \\
\text { Yellow }\end{array}$ & Sherwin Williams & 75 \\
\hline Thermoplastic & $\$ 0.25 /$ foot & As needed & $\begin{array}{l}\text { Asphalt, } \\
\text { Concrete }\end{array}$ & $\begin{array}{l}\text { White, } \\
\text { Yellow }\end{array}$ & Hot Tape and others & 14 \\
\hline Epoxy & $\$ 0.35 /$ foot & $4-5$ & $\begin{array}{c}\text { Asphalt } \\
\text { Concrete }\end{array}$ & $\begin{array}{l}\text { White, } \\
\text { Yellow }\end{array}$ & Epoplex and others & 7 \\
\hline $\begin{array}{c}\text { Methyl } \\
\text { methacrylate }\end{array}$ & $\begin{array}{l}\text { Not } \\
\text { Used }\end{array}$ & N/A & N/A & N/A & N/A & 0 \\
\hline $\begin{array}{l}\text { Conventional } \\
\text { solvent paints }\end{array}$ & $\begin{array}{l}\text { Not } \\
\text { Used }\end{array}$ & N/A & N/A & $\mathrm{N} / \mathrm{A}$ & N/A & 0 \\
\hline Polyester & $\begin{array}{l}\text { Not } \\
\text { Used }\end{array}$ & N/A & N/A & N/A & N/A & 0 \\
\hline Polyurea & $\begin{array}{l}\$ 0.75 / \mathrm{ft} \\
\text { by } \\
\text { contract }\end{array}$ & $4-5$ & $\begin{array}{l}\text { Asphalt, } \\
\text { Concrete }\end{array}$ & $\begin{array}{l}\text { White } \\
\text { Yellow }\end{array}$ & Epoplex and 3M & 1 \\
\hline Preformed tapes & $\begin{array}{l}\$ 2.75 / \mathrm{ft} \\
\text { by } \\
\text { contract }\end{array}$ & $7-8$ & $\begin{array}{l}\text { Asphalt, } \\
\text { Concrete }\end{array}$ & White & 3-M & 3 \\
\hline $\begin{array}{l}\text { 1. We've a } \\
\text { interstat } \\
\text { 2. Device }\end{array}$ & $\begin{array}{l}\text { used a pc } \\
\text { Don't kno } \\
\text { del: LTL }\end{array}$ & $\begin{array}{l}\text { urethane or m } \\
\text { the cost and } \\
00 \text { (Manufact }\end{array}$ & $\begin{array}{l}\text { ied epoxy b } \\
\text { ave not repl } \\
\text { : Delta) is us }\end{array}$ & $\begin{array}{l}\text { Ennis Paint } \\
\text { ed it yet. It } \\
\text { l to measur }\end{array}$ & $\begin{array}{l}\text { HPS 4) on concrete on } \\
\text { s about } 3 \text { years old. } \\
\text { retroreflectivity. }\end{array}$ & \\
\hline
\end{tabular}


Table 15. Use of Pavement Marking Materials in LaPorte District

\begin{tabular}{|c|c|c|c|c|c|c|}
\hline \multicolumn{7}{|c|}{ Pavement Materials in Fort Wayne District } \\
\hline Material & $\begin{array}{c}\text { Cost } \\
(\$ / \text { foot })\end{array}$ & $\begin{array}{l}\text { Service Life } \\
\text { (Year) }\end{array}$ & $\begin{array}{c}\text { Pavement } \\
\text { Types }\end{array}$ & $\begin{array}{l}\text { Marking } \\
\text { Colors }\end{array}$ & Brand/Manufacturer & $\begin{array}{c}\% \\
\text { Usage }\end{array}$ \\
\hline $\begin{array}{l}\text { Waterborne } \\
\text { Paints }\end{array}$ & $\begin{array}{c}\$ 0.23 / \mathrm{ft} \\
\text { by } \\
\text { contract; }< \\
0.05 \text { by } \\
\text { INDOT }\end{array}$ & 1 & $\begin{array}{l}\text { Asphalt, } \\
\text { Concrete }\end{array}$ & $\begin{array}{l}\text { White, } \\
\text { Yellow }\end{array}$ & Sherwin Williams & 69 \\
\hline Thermoplastic & $\begin{array}{c}\$ 0.34 \text { to } \\
\$ 0.37 / \mathrm{ft} \\
\text { by } \\
\text { contract }\end{array}$ & $2-3$ & Asphalt & $\begin{array}{l}\text { White, } \\
\text { Yellow }\end{array}$ & Hot Tape and others & 15 \\
\hline Epoxy & $\begin{array}{l}\$ 1.16 / \mathrm{ft} \\
\text { by } \\
\text { contract }\end{array}$ & $3-4$ & $\begin{array}{l}\text { Asphalt, } \\
\text { Concrete }\end{array}$ & $\begin{array}{l}\text { White, } \\
\text { Yellow }\end{array}$ & Poly/Carb & 15 \\
\hline $\begin{array}{c}\text { Methyl } \\
\text { methacrylate }\end{array}$ & $\begin{array}{l}\text { Not } \\
\text { Used }\end{array}$ & N/A & N/A & N/A & N/A & 0 \\
\hline $\begin{array}{l}\text { Conventional } \\
\text { solvent paints }\end{array}$ & $\begin{array}{l}\text { Not } \\
\text { Used }\end{array}$ & N/A & N/A & N/A & N/A & 0 \\
\hline Polyester & $\begin{array}{l}\text { Not } \\
\text { Used }\end{array}$ & N/A & N/A & N/A & N/A & 0 \\
\hline Polyurea & $\begin{array}{c}\text { Not } \\
\text { Used }\end{array}$ & N/A & N/A & N/A & N/A & 0 \\
\hline Preformed tapes & $\begin{array}{c}\$ 1.16 / \mathrm{ft} \\
\text { by } \\
\text { contract }\end{array}$ & 2 & $\begin{array}{l}\text { Asphalt, } \\
\text { Concrete }\end{array}$ & $\begin{array}{l}\text { White, } \\
\text { Yellow }\end{array}$ & 3-M \& MGI & 1 \\
\hline
\end{tabular}

As shown in the survey, the pavement marking materials used in the Vincennes District include waterborne paints, thermoplastic, epoxy, and preformed tapes. In the Vincennes District, the usages of the marking materials are $99 \%$ of the waterborne paints and less than $1 \%$ of each of the other types. In the Fort Wayne District, the pavement marking materials include waterborne paints, thermoplastic, epoxy, polyurea, and preformed tapes, with usages of $74 \%, 14 \%, 7 \%, 1 \%$, and 3\%, respectively. In LaPorte District, the materials used are waterborne paints, thermoplastic, epoxy, and preformed tapes, with usages of $69 \%, 15 \%, 15 \%$, and 1\%, respectively. The Fort Wayne District 
also used polyurethane or modified epoxy on concrete pavement on interstate highways. This new materials have been installed for three years and have not been replaced yet.

The installed costs of these marking materials and service lives are listed in Table 16. As can be seen, the most extensively used pavement marking material, waterborne paint, has the shortest service life. However, the cost of waterborne paint is not necessarily lower than other materials.

Table 16. Costs and Service Lives of Pavement Marking Materials in INDOT Districts

\begin{tabular}{|c|c|c|c|c|c|c|c|c|c|c|c|c|}
\hline \multirow{2}{*}{ Material } & \multicolumn{6}{|c|}{ Cost (\$/foot) } & \multicolumn{6}{|c|}{ Service Life (Year) } \\
\hline & $\mathrm{C}$ & $\mathrm{F}$ & $\mathrm{G}$ & $\mathrm{L}$ & $\mathrm{S}$ & $\mathrm{V}$ & $\mathrm{C}$ & $\mathrm{F}$ & G & $\mathrm{L}$ & $\mathrm{S}$ & $\mathrm{V}$ \\
\hline Waterborne Paints & & $0.2-0.5$ & & $0.05-0.23$ & & 0.5 & & 1 & & 1 & & 1 \\
\hline Thermoplastic & & 0.25 & & $0.24-0.37$ & & 0.2 & & & & $2-3$ & & $3-5$ \\
\hline Epoxy & & 0.35 & & 1.16 & & & & $4-5$ & & $3-4$ & & 3 \\
\hline Methyl methacrylat & & & & & & & & & & & & \\
\hline $\begin{array}{c}\text { Conventional solven } \\
\text { paints }\end{array}$ & & & & & & & & & & & & \\
\hline Polyester & & & & & & & & & & & & \\
\hline Polyurea & & 0.75 & & & & & & $4-5$ & & & & \\
\hline Preformed tapes & & 2.75 & & 1.16 & & & & $7-8$ & & 2 & & $1-5$ \\
\hline
\end{tabular}




\section{CHAPTER 4. SUMMARY AND RECOMMENDATIONS}

Through this synthesis study, the key information on pavement marking materials and retroreflectivity measuring equipment in this country has been obtained. The practices of pavement markings in several INDOT districts have also been surveyed through questionnaire. The major findings of this synthesis study are summarized as follows.

\subsection{Performance of Pavement Marking Materials}

Waterborne traffic paints are the most widely used pavement marking material in the nation. Compared to other pavement marking materials, waterborne paints wear off rapidly and lose retroreflectivity quickly after being exposed to factors such as high traffic volumes and winter maintenance activities. The literature shows that the service lives of waterborne paint markings are generally about one year or even shorter. Because of the short service life of waterborne paint markings, many state agencies often choose to repaint those markings on a fixed schedule instead of restriping when some objective measure such as retroreflectivity drops below a specified threshold. With the easy availability of more durable pavement marking materials on the market, Gates et al. (2003) suggested that waterborne paint is not a suitable marking material for high-volume roadways despite its inexpensive application cost. 
The study for Missouri DOT's District 7 developed a pavement marking management system to address the issues of quality control and quality assurance (Weinkein, Branham, and Ginder, 2002). The study concluded that using large beads in waterborne paints would improve the performance of pavement markings. The large beads could provide better wet nighttime retroreflectivity and reduce "paint on vehicle" complaints. The Missouri study also found that heavier applications of waterborne paints could increase the retroreflectivity of pavement markings. Based on the evaluation results, the Missouri study provided a list of recommendations as shown in the previous chapter. It is believed that the recommendations are useful information for INDOT to consider with respect to pavement markings.

Conventional solvent paints are single-component paints that contain a binder resin, pigments or fillers, and solvents or additives. Due to the ingredients used in the formulation of these paints, they typically contain $440 \mathrm{~g} / \mathrm{L}(3.70 \mathrm{lb} / \mathrm{gal})$ of VOCs, far exceeding the maximum of $150 \mathrm{~g} / \mathrm{L}(1.25 \mathrm{lb} / \mathrm{gal})$ recommended by the EPA. The use of these paints have gradually diminished with the introduction of the EPA limits on VOCs.

Thermoplastics materials consist of four basic components: binder, pigment, glass beads, and filler (sand or calcium carbonate). Due to its low VOC content, moderate cost and durability, thermoplastic is one of the most widely used pavement marking materials. One of the advantages of using thermoplastic is that the material can be re-applied over older thermoplastic markings, thereby refurbishing the older marking as well as saving on the costs of removing old pavement markings. Although thermoplastic materials usually 
perform very well on all types of asphalt surfaces, there have been mixed results when they have been applied on concrete pavements. Some state DOTs have had great success with thermoplastic markings on concrete, while many others discontinue its use for concrete pavements. One of the disadvantages of thermoplastic is its color and appearance. Thermoplastic is grayish, making it less visible by day, and has a tendency to crack. Further, the application of thermoplastic marking materials in areas with colder climates is limited due to the poor adhesion of the material to pavement surfaces in lower temperatures. Successful thermoplastic performance on concrete is highly dependent on correct thermoplastic material formulation, proper surface cleaning, moisture removal, and priming (if necessary) before installation.

Several types of tapes are currently in use, including flat preformed tape and profiled preformed tape. Tapes tend to have a high initial cost and are generally used in areas that require minimal marking and need to perform under severe conditions. Glass beads that provide retroreflectivity in tapes are incorporated into material during factory manufacturing. Freshly installed tape markings typically have initial retroreflectivity values four to six times that of waterborne traffic paints. However, tapes may lose their retroreflectivity rapidly and their useful life may be as little as three years. If applied properly, tape will provide between 4 and 8 years of use. The successful performance on tape depends on many stringent requirements, including proper pavement and air temperature, adequate preparation of the surface (e.g., dry and free of existing markings), the use of quality adhesives (if markings are overlaid), and the need for proper curing 
time. Nevertheless, according to many agencies, the advantages of using preformed tape appear to outweigh the disadvantages or strict requirements.

Epoxy is a type of two-component material that is produced on site through the reaction of two separate chemical reactants. The strong bond that forms between epoxy paints and both asphalt and concrete pavement surfaces results in the material being highly durable when applied on both pavement surfaces. In addition, epoxy markings have low VOC content, but the chemicals used to produce them are classified as hazardous materials. The first component of the epoxy typically contains resin, pigment, extenders, and fillers, while the second component acts as a catalyst to accelerate setting time. Epoxy markings are generally considered to have moderate cost and have a service life of 2 to 4 years. The epoxy stripes have been shown to discolor with age, particularly when exposed to intense ultraviolet light. Many epoxy materials require long drying times (sometimes more than 40 minutes) that limit the use of this material under high traffic conditions. Regardless of its shortcomings, a survey conducted by Gates et al. (2003) found that more agencies used epoxy markings on concrete surfaces with high traffic volumes than any other pavement marking material, although the majority of the agencies responding to the survey selected preformed tape as the top performer on concrete.

Methyl methacrylate markings are highly durable and can be sprayed or extruded but generally require long no-track times. Methyl methacrylate is an attractive pavement marking material because it can be applied in low temperatures, is resistant to oils, anti- 
freeze, and other chemicals commonly found on roadways, and bonds well to both asphalt and concrete surfaces. Literature revealed that the use of methyl methacrylate pavement markings is still very limited in the United States. Of the 19 state agencies surveyed, only Oregon, Alaska and California used methyl methacrylate pavement markings. All three states rated the material very highly. In California and Alaska, methyl methacrylate pavement markings were found to outperform thermoplastic and paint markings in terms of durability, cost, visibility, and service life when applied in heavy snowfall areas.

Polyester marking materials are produced onsite through the mixture of two separate groups of reactants (chemicals) immediately before application. Glass beads are dropped onto the surface of the stripe while it is still wet to provide retroreflectivity. Polyester is best used on asphalt pavements and can be applied over existing markings. Although polyester markings have low VOC content, the chemicals used to produce the material are classified as hazardous materials (Andrady, 1997).

Polyurea is a two-component material that is produced onsite through the chemical reaction of two separate components. Glass beads are dropped onto the wet surface to provide retroreflectivity. Polyurea is a relatively new pavement marking material that is often marketed by manufacturers as a durable marking material that maintains good color stability when exposed to ultraviolet light, cures quickly (3 to 8 minutes at all temperatures), may be applied at low ambient pavement surface temperatures (as low as $40^{\circ} \mathrm{F}$ ), is not affected by humidity, and works equally well on 
asphalt and concrete pavements. Initial findings suggest that while the material is highly durable, the durability and abrasion resistance of the ceramic elements that enhance the retroreflectivity of the material is questionable. A major disadvantage identified was the need for special equipment and high cost compared to most other marking materials.

The Virginia Department of Transportation (VDOT) studied the effectiveness of pavement markings (Cottrell and Hanson, 2001). They drew the following conclusions on cost-effectiveness:

- The large paint contract is the most cost-effective for two-lane roads under most traffic volume conditions and for four- and six-lane low-volume roads. Polyurea and paint installed under a large-scale contract are the most cost-effective for high-volume four-lane roads, and polyurea and waffle tape are the most costeffective for high-volume six-lane roads.

- For durable markings, the order from most to least cost-effective is polyurea, thermoplastic, epoxy, and waffle tape for the low-volume roads. For higher volume roads, the order is polyurea, waffle tape, thermoplastic, and epoxy. When only the annualized installation costs are considered for a study period of 6 years, the order from least to most expensive is thermoplastic, epoxy, polyurea, and waffle tape.

The Federal Highway Administration (FHWA) sponsored TRB to evaluate the service life of durable, longer lasting pavement markings (Migletz, Graham, \& Bauer, 2001). In order to measure the service life, threshold retroreflectivity values were used to 
define the end of a pavement marking service life. The researchers established the threshold values and service lives of various marking materials shown in Tables 3, 4, and 5 in the previous chapter.

A Minnesota study (Montebello and Schroeder 2000) was performed to provide guidelines for pavement markings in county and city highways. The study found that for roadways with high AADT (10,000 or more), a more durable product may be a better alternative than paint because it can reduce worker exposure to traffic and maintain a visible line for at least one to four years. Bead application plays an important role in the retroreflectivity of all pavement marking materials. Proper application can lead to increased nighttime visibility and greater line durability.

Gates, Hawkins, and Rose (2003) conducted a study to determine the durability of various pavement materials on concrete pavements in Taxes. The researchers recommended that epoxy materials and preformed tapes be used for pavement markings on PCC roadways and that thermoplastic only be used for short-term applications with low to medium traffic. Tables 7, 8 and 9 in the previous chapter contain more detailed information on pavement markings on concrete pavement.

\subsection{Retroreflectivity Measuring Devices}

A study for the Alabama Department of Transportation (Lindly, Yellapu, and Supriyasilp, 2002) performed field-testing and analysis of two competing pavement 
marking retroreflectometers: the Laserlux and the LTL2000. The cost analysis of the two retroreflectometers indicates that the Laserlux would be the more cost effective retroreflectometer. The cost to test pavement marking for an eight-year period is estimated approximately $\$ 5 /$ mile of marking per year for the Laserlux and approximately \$35/mile of marking per year for the LTL2000. Only one Laserlux and one crew would be required to perform the testing. Eight LTL2000s and eight crews would be required to perform the same job. The study determined that the mileage break point was approximately 580 miles of two-lane road system per year. That is, if it is needed to measure more the 580 miles of pavement markings on a two-lane road system per year, the Laserlux would be less costly than the LTL 2000 devices.

Missouri DOT's experience with the retroreflectivity measurement showed that the Laserlux retroreflectivity readings are more accurate and thorough than the handheld Mirolux 30. The Laserlux mobile unit can take 70,000 measurements per hour at highway speeds and can measure an area of 3.5 feet in width continuously without traffic control. Handheld units require workers to be on the roadway to actually take the readings, which requires traffic control.

The information on current prices and models of various types of devices is given below:

- 71000 StripeMaster Pavement Marking Retroreflectometer: \$14,985. One year warranty. 
- 75000 Stripemaster II Pavement Marking Retroreflectometer with Internal Printer and GPS: \$17,500. One year warranty.

- $\quad$ 1200F Field Raised Pavement Marker with data logger ASTM Geometry (0.2 OBSRV): \$17,500. One year warranty.

- Laserlux: $\$ 150,000$ to $\$ 180,000$ (including a van, training for 2 or 3 operators, and one year parts and labor warranty). (Note: \$180,000 has additional options, such as the second year maintenance, video overlay, etc.)

- LTL-X: \$18,600. 30-meter geometry pavement marking retroreflectometer with integrated GPS, measuring nighttime visibility of pavement markings. One year warranty.

- QD30: \$17,220. Pavement marking daytime retroreflectometer, measuring daytime brightness (as viewed by driver) of markings and road surfaces. One year warranty.

\subsection{Recommendations}

As the literature clearly shows, waterborne paints are the most commonly used pavement marking material in this country. It is also apparent that pavement markings of waterborne paints generally have a service life of one year or less. Attempts have been made by many researchers in other states to improve the quality and durability of pavement markings. The quality of pavement markings is affected by many factors, such as the marking materials, thickness of marking, installation of marking, type of pavement, traffic volume, weather condition, and snow/ice removal operations. It is, therefore, 
important for INDOT to identify the effects of these factors on the effectiveness of various types of pavement markings in Indiana. This can be achieved through a systematic evaluation of pavement markings on different pavements at selected locations. During the evaluation period, the conditions of the pavement markings will be examined and the retroreflectivities will be measured at regular time intervals, such as very six or twelve months. It is expected that the evaluation would last at least three years to obtain sufficient information on the performance and cost effectiveness of pavement marking materials. The evaluation would provide a basis for INDOT to select appropriate marking materials for different pavements and traffic conditions.

A logical step following the evaluation would be for INDOT to develop a pavement marking management system (PMMS). The PMMS would utilize the results of the evaluation project, such as threshold values of retroreflectivity, service lives, and costs of pavement markings, to optimize repaint schedules. In the PMMS, GIS and GPS technologies should be incorporated for INDOT engineers and planners to monitor and manage the pavement markings on the Indiana highway system.

Through this synthesis study, it is recommended that INDOT take the following two steps to improve the effectiveness of the Indiana pavement markings. The first step is to conduct an evaluation project to identify appropriate materials and methods to improve the quality of pavement markings. The evaluation project should consider the following factors: 
1. Pavement Marking Materials: The materials to be evaluated will include waterborne paints, thermoplastics, epoxy, preformed types, and others. Large and small beads will be evaluated in combination with marking materials. Different thicknesses of waterborne paint markings will be placed in selected road sections.

2. Pavement Types: Concrete and asphalt pavements will be included in the evaluation.

3. Highway Types: Two-lane and multi-lane highways will be evaluated for pavement markings.

4. Traffic Conditions: Road sections with high, medium, and low traffic volumes will be included. The road sections should be selected near weigh-in-motion stations, so that traffic volumes and composites (types of vehicles) will be obtained for analysis.

5. Weather Conditions: To reflect the effects of weather conditions on pavement markings, test road sections should be selected in northern, middle, and southern parts of Indiana.

6. Retroreflectivity Measurement Equipment: Retroreflectivity can be measured with handheld or mobile equipment. However, it is recommended to purchase a Laserlux for the evaluation project as well as for a statewide retroreflectivity measurement and inventory.

On the selected road sections, pavement markings will be place with specified materials and then the initial retroreflectivity values will be measured. During the following years of the evaluation, retroreflectivity values of the road sections should be measured twice per year. Photos will be taken of the pavement markings each year and problems, such as 
cracking and peeling of markings, will be recorded each year. The evaluation project should be monitored for at least three years, preferably five years for durable marking materials. The results of the evaluation project will include 1). The durability and performance of marking materials; 2). Cost effectiveness of marking materials; and 3). Establishment of minimum retroreflectivity values for new pavement markings and threshold retroreflectivity values for repainting old pavement markings.

The second step should be taken after the evaluation project. This step will be the development of an INDOT Pavement Marking Management System (PMMS). The PMMS will provide tools for INDOT to plan, monitor, schedule, and select pavement marking projects. The information on INDOT pavement markings will be stored with GPS and GIS technologies in terms of location, marking material, age, retroreflectivity, traffic volume, etc. Low retroreflectivity markings will be highlighted and future retroreflectivity values will be predicted for planning and management purposes. Pavement marking repainting projects will be prioritized based on established criteria. 


\section{REFERENCES}

Ahmad, I., Najafi, T. F., Benham, L. J., \& Lancaster, P. (2001). An Investigation of Application and Bonding Strengths of Thermoplastic Pavement Markings: A comparison between Concrete and Asphalt Roadway Surfaces. Final Report, FIU Project No. 571839200, Florida International University and Florida Department of Transportation.

Andrady, A. L. (1997). Pavement Marking Materials: Assessing Environment-Friendly Performance. NCHRP Report 392. Washington, D.C., Transportation Research Board.

Bahar, G., Masliah, M., Erwin, T., Tan, E., \& Hauer, E. (2006). Pavement Marking Materials and Markers: Real-World Relationship between Retroreflectivity and Safety Over Time. Final Report for NCHRP Project 17-28.

Clark, J., \& Sanders, S. (1993). Review and Recommendations for Pavement Marking Materials. Department of Civil Engineering, Clemson University, S.C.

Cottrell, B. H., \& Hanson, R.A. (2001). Determining the Effectiveness of Pavement Marking Materials. Final Report, VTRC 01-R9, Virginia Transportation Research Council, Charlottesville, Virginia.

Gates, J. T., Hawkins G.H, \& Rose, E. R. (2003). Effective Pavement Marking Materials and Applications for Portland Cement Concrete Roadways. FHWA/TX-03/4150-2, Texas Transportation Institute.

Gates, T. J., Hawkins, H. G., and Rose, E. R. (2003). Effective Pavement Marking Materials and Applications for Portland Cement Concrete Roadways. Report 4150-2, Texas Transportation Institute, College Station, Texas.

Gates, T.J., Hawkins, H.G., \& Rose, E.R. (2003). Effective Pavement Marking Materials and Applications for Portland Cement Concrete Roadways. Texas DOT Project Number 0-4150, Report 4150-2. Texas Transportation Institute.

Henry, J., Antle, C., \& Carroll, J. (1990). Service Life and Cost of Pavement Marking Materials. Pennsylvania Transportation Institute.

Lee, J., Maleck, T., \& Taylor, W. (1999). Pavement Marking Material Evaluation Study in Michigan. ITE Journa.

Lindly, J.K., Yellapu, K., \& Supriyasilp, T. (2002). Evaluation of Retroreflectometers for the Alabama Department of Transportation. Report 02402, University of Alabama, Tuscaloosa, Alabama.

McGinnis, R.G. (2001). Pavement Markings Benchmarking. FHWA-PA-2001-027-97-04(83), Pennsylvania Transportation Institute.

Migletz, J. \& Graham, J. (2002). Long-Term Pavement Marking Practices. National Cooperative Highway Research Program Synthesis 306, Washington, D.C., Transportation Research Board.

Migletz, J., Fish, J.K., \& Graham, J.L. (1994). Roadway Delineation Practices Handbook, FHWASA-93-001. Federal Highway Administration, Washington, D.C. 
Migletz, J., J. Graham, D. H., \& Bauer, K. (2001). Service Life of Durable Pavement Markings. Paper 010-447. Transportation Research Board 80th Annual Meeting Preprint CD-ROM. Transportation Research Board, National Research Council, Washington, D.C.

Montebello, D., \& Schroeder, J. (2000). Cost of Pavement Marking Materials. Final Report, Minnesota Local Road Research Board, St Paul, Minnesota.

Thomas, G.B. \& Schloz, C. (2001). Durable, Cost-Effective Pavement Markings Phase I: Synthesis of Current Research. Iowa DOT Project TR-454, Final Report. Iowa State University.

TransTech Management Inc. (2001). Synthesis of Practice for AASHTO's National Transportation Product Evaluation Program. NCHRP 20-7 Task 143 Draft Report.

Weinkein, D., Randy Branham, R., \& Ginder, V. (2002). District 7 Report on Phase 1 and 2 on the Pavement Marking Management System Research Projects. Project RI-98029. Missouri Department of Transportation, District 7, Joplin, Missouri. 